\title{
Estudio geológico y bioestratigráfico del Paleozoico del Complejo Maláguide en la Zona de Cogollos Vega (Granada) mediante conodontos
}

\author{
Ángela Cabrera-Porras ${ }^{(1)}$, Rosario Rodríguez-Cañero(1) y Agustín Martín-Algarra(2) \\ (1) Avda. Severo Ochoa s/n, Dpto. Estratigrafía y Paleontología, Universidad de Granada, 18071 Granada. \\ angelacabrera5@correo.ugr.es,charorc@ugr.es \\ (2) Avda. Severo Ochoa s/n, Dpto. Estratigrafía y Paleontología e IACT-CSIS, Uni versidad de Granada, 18071 Granada. \\ agustin@ugr.es
}

\section{RESUMEN}

La integración de datos cartográficos, litoestratigráficos y estructurales con el estudio de la fauna de conodontos hallada ha permitido detallar diversos aspectos de la geología del Complejo Maláguide en la Zona de Cogollos Vega. La Formación Falcoña constituye un importante nivel-guía para la correlación de distintas secciones estratigráficas presentes en el área. Su presencia ha permitido diferenciar las sucesiones pre-Falcoña y post-Falcoña, con facies y edades diferentes: la primera del Devónico (Emsiense, Frasniense y Fameniense) y la segunda del Carbonífero (Viseense superior-Serpukhoviense inferior). La estructura Alpina de la zona está determinada por la existencia de retrocabalgamientos que producen repeticiones de la serie estratigráfica general y pliegues asociados vergentes al sur que organizan el Complejo Maláguide en tres unidades tectónicas. Las estructuras están sistemáticamente cortadas y desplazadas por fallas normales y de salto en dirección dextrorsas, orientadas predominantemente según NW-SE. Un análisis preliminar del Índice de Alteración del Color (CAl) y de las microtexturas de los elementos conodontales ha revelado interesantes diferencias entre las unidades tectónicas presentes en la zona, lo que deberá ser objeto de estudio más detallado.

Palabras clave: Béticas, bioestratigrafía, cartografía geológica, conodontos, Índice de Alteración del Color (CAl).

\section{A geological and biostratigraphic study of the Paleozoic of the Malaguide Complex in the Cogollos Vega Zone (Granada) using conodonts}

\begin{abstract}
A detailed geological characterization of the Malaguide Complex in the Cogollos Vega Zone has been made by integrating geological mapping, lithostratigraphy and structural analysis with conodont studies. The Falcoña Formation constitutes an important guide-horizon to correlate different stratigraphic sections and to distinguish pre-Falcoña and post-Falcoña successions with slightly different facies and different ages: the first one is Devonian (Emsian, Frasnian and Famennian) and the second one Carboniferous (upper Visean-lower Serpukhovian). The Alpine structure of the area is determined by the presence of backthrusts associated with south-vergent folds that repeat the general stratigraphy and divide the Malaguide Complex into three tectonic units. These structures are systematically cut by (mainly NW-SE oriented) normal and dextral strike-slip faults. Preliminary Colour Alteration Index (CAI) and micro-textural studies of conodontal elements have revealed interesting differences between the tectonic units present in the area, which should be the subject of a more detailed study.
\end{abstract}

Keywords: Betics, biostratigraphy, conodonts, geological mapping, Colour Alteration Index (CAl). 


\section{Introducción}

En la Cordillera Bética, los conodontos constituyen el grupo fósil de mayor interés para establecer la bioestratigrafía y paleogeografía pre-Alpinas, en particular la del Paleozoico del Complejo Maláguide (Rodríguez-Cañero, 1993; Navas-Parejo, 2012; Rodríguez-Cañero and Martín-Algarra, 2014 y referencias allí incluidas) y, recientemente también, la del Complejo Nevado-Filábride (Rodríguez Cañero et al. 2018; Martín-Algarra et al. 2019). Además de su aplicación en la bioestratigrafía, el estudio de su índice de alteración del color (CAI) proporciona una información relevante sobre la historia térmica a la que ha podido estar sometida la roca que los contiene $y$, por ende, puede ayudar a dilucidar la historia geológica de esta complicada zona de la Cordillera Bética

El objetivo de este trabajo se ha centrado en el estudio litoestratigráfico y cartográfico de diversas secciones localizadas en el afloramiento del Complejo Malaguide en la Zona de Cogollos Vega (ZCV) en la provincia de Granada (Fig. 1), así como en la bioestratigrafía de sus niveles de calizas mediante conodontos, en los que también se ha realizado una determinación preliminar de los valores del CAl y de los cambios texturales asociados a su recristalización diagenético-metamórfica. Se han localizado y estudiado once nuevas secciones y revisado otras tres, previamente descritas por diferentes autores (Fig. 3).

\section{Localización y contexto geológico}

El área de estudio se sitúa en la Sierra de Huétor al $\mathrm{N}$ de la ciudad de Granada (Fig. 1B). Forma parte del sector central de una región topográficamente deprimida, que constituye el mayor afloramiento del Complejo Maláguide en la provincia de Granada. Esta zona fue estudiada por primera vez por Blumenthal and Fallot (1935), quienes la denominaron Zona de Cogollos Vega (ZCV).

El Complejo Maláguide forma parte de las Zonas Internas de la Cordillera Bética (Fig. 1) y se diferencia de los otros complejos internos por presentar una sucesión estratigráfica paleozoica bien desarrollada y no afectada por el metamorfismo alpino, o ser éste de bajo grado y solo reconocible en sus unidades tectónicas más profundas (Ruiz Cruz and Nieto, 2002; RuizCruz, et al. 2005; Vera, 2004). Este complejo (Fig. 1A) fue originalmente definido en la provincia de Málaga por Blumenthal (1927), quien lo denominó “Bético de Málaga". Más tarde, pasaría a ser denominado Complejo Maláguide por Durand-Delga (1968) tras localizarlo en pequeños afloramientos que se encuentran dispersos en el Corredor de las Alpujarras.
El Complejo Malaguide en la ZCV presenta un Paleozoico bien desarrollado, compuesto principalmente por rocas sedimentarias marinas de litología pizarroso-grauváquica, localmente afectadas por metamorfismo de bajo grado. Estos materiales se incluyen en el Grupo Piar (Martín-Algarra et al. 2004) que, de abajo a arriba, está constituido por las formaciones Santi Petri, Falcoña, Almogía y Marbella, además de por otros terrenos cuya asignación litoestratigráfica precisa está aún pendiente de realizar. La Formación Morales no se ha encontrado claramente representada en el área de estudio, pero aparece en diferentes afloramientos del Complejo Maláguide por debajo de la Formación Santi Petri. Discordantemente sobre el Paleozoico aparece la Formación Saladilla compuesta por sedimentos terrígenos de color rojizo del Triásico, sobre los que se depositó una secuencia marina del Jurásico al Mioceno inferior que está mal expuesta en la ZCV.

\section{Formaciones del Complejo Maláguide presentes en el área de estudio}

Formación Santi Petri (Michelau, 1941). Está caracterizada por unas típicas facies calcáreas replegadas denominadas calizas alabeadas, término introducido por Orueta (1917). Se le atribuye una edad pre-Carbonífera (Devónica) por su posición estratigráfica.

Formación Falcoña (Herbig, 1983). Está formada a su base por radiolaritas negras (liditas) del Tournaisiense y a techo por calizas azuladas del Viseense superior, según las dataciones realizadas en los Montes de Málaga mediante radiolarios y conodontos (Rodríguez-Cañero and Guerra-Merchán, 1996; O’Dogherty et al. 2000). Esta formación constituye el mejor nivel-guía del Paleozoico maláguide.

Formación Almogía (Mon, 1971). Es un conjunto de depósitos turbidíticos en facies Culm, la tectofacies sinorogénica de la Orogenia Varisca. Forma una megasecuencia granodecreciente, con predominio de grauvacas y conglomerados (Miembro Retamares: Kockel and Stoppel, 1962).

Formación Marbella (Michelau, 1941; Blumenthal, 1949; Herbig, 1984). Se encuentra en el techo del Grupo Piar, disconforme sobre la Fm. Almogía. Es un conglomerado con matriz areniscosa gruesa y características de flujos de derrubios (debris flow), que incluye cantos y bloques de calizas, dolomías, granitos y gneises de procedencia desconocida, además de clastos de filitas, esquistos, pizarras y cuarcitas. La edad de la formación es post-Bashkiriense basal ya que los clastos de calizas contienen facies y fósiles pertenecientes a plataforma somera del Viseense superior al Bashkiriense basal y 


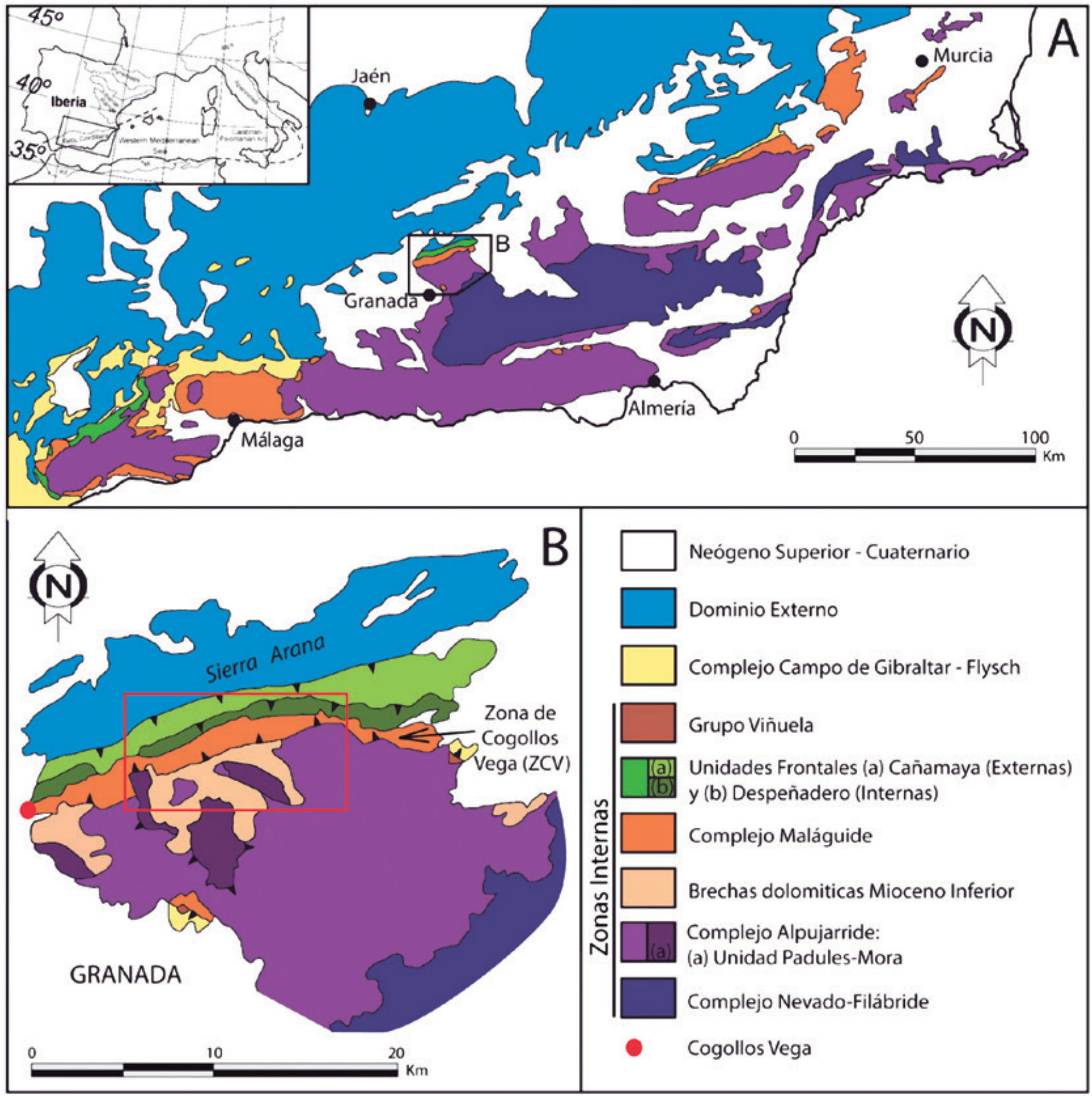

Figura 1. A: Mapa geológico general de la Cordillera Bética donde se muestran los principales dominios que la componen. B: Principales unidades tectónicas presentes en la zona de estudio. El recuadro rojo presenta la localización de la figura 2 (modificada de Navas-Parejo, 2012).

Figure 1. A: General map of the Betic Cordillera where its main domains are shown. B: Main tectonic units of the study area. The red box indicates the location of Figure 2 (modified from Navas-Parejo, 2012).

facies pelágicas con conodontos del Carbonífero inferior (Herbig, 1984; y Herbig and Mamet, 1985).

Formación Saladilla. Definida por Soediono (1971), se depositó discordantemente sobre los materiales paleozoicos. Destaca por su color rojizo y está dominada por arcillitas y limolitas con intercalaciones de areniscas $\mathrm{y}$, localmente, de conglomerados. Su edad es Triásico, de acuerdo con dataciones realizadas mediante polen en otras áreas fuera de la ZCV (Martín-AIgarra et al. 1995).

Materiales del Jurásico, Cretácico y Paleógeno. En el área de estudio estos materiales afloran sólo muy 


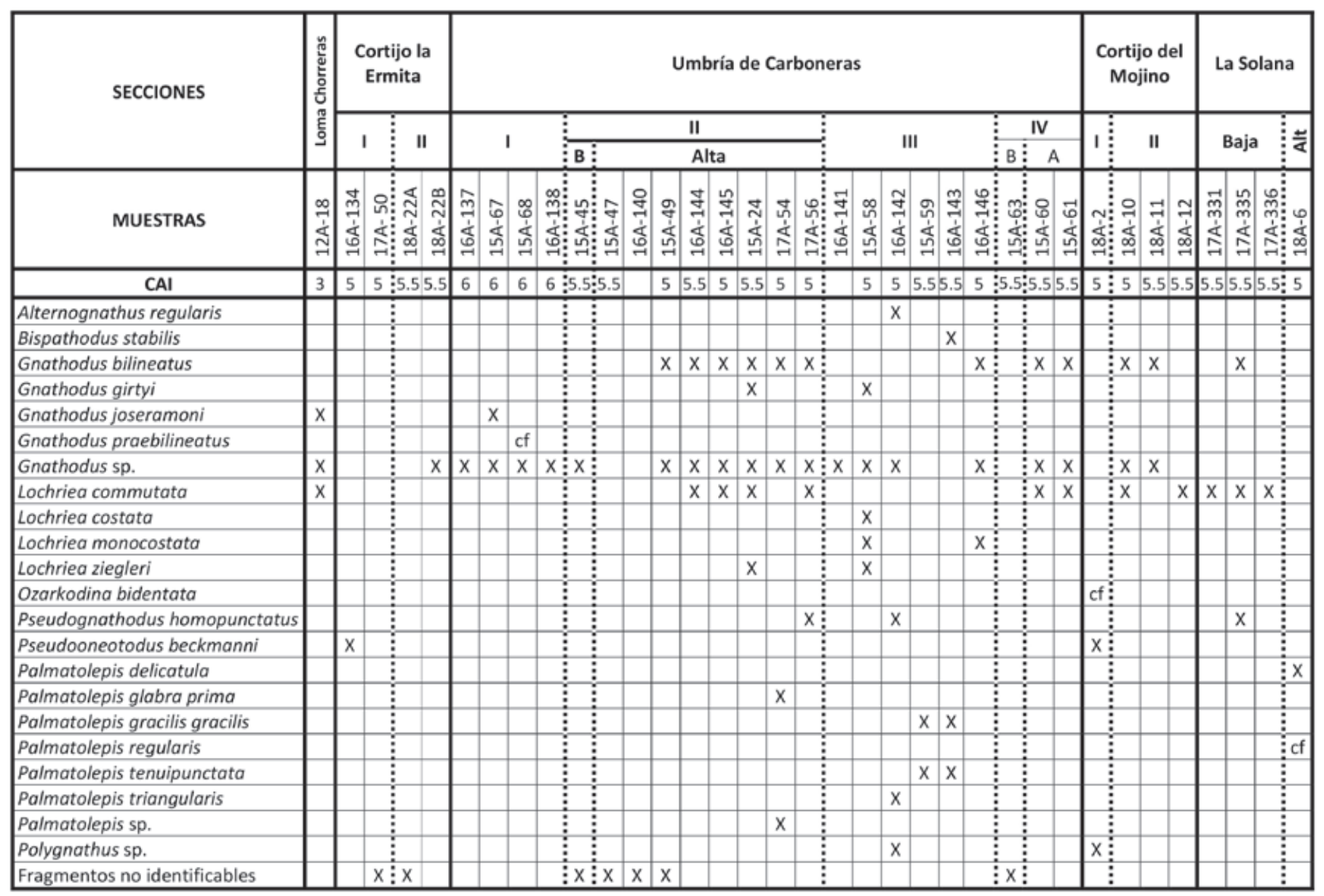

Tabla 1. Secciones y muestras estudiadas, con las correspondientes especies y géneros de conodontos que aparecen en cada una de ellas. Table 1. Studied sections and samples, with the corresponding conodont species and genera that appear in each of them.

localmente, con escasa potencia y fuertemente tectonizados. Destacan los atribuidos al Jurásico y Cretácico Inferior: dolomías, calizas grises y blancas con facies marinas someras y alternancias calizo-margosas hemipelágicas o pelágicas, respectivamente asignables a las formaciones Castillón y Vélez Rubio (Geel, 1973). También aparecen esporádicamente calizas con alveolinas y nummulites del Eoceno, asignables a la Formación Malvariche (Martín-Martín, 1996).

Sucesión de pelitas, grauvacas y calizas con conodontos y dacrioconáridos. Una parte importante de los terrenos estudiados está dominada por pizarras y grauvacas que muestran litofacies banales, muy semejantes -cuando no idénticas- a las presentes en las distintas formaciones paleozoicas antes mencionadas. Sin embargo, entre ellas a veces aparecen pequeños lentejones calizos con fósiles del Devónico. En otras áreas del Complejo Maláguide (Ardales, Almogía y Corredor de Vélez Rubio, ver en Fig. 1 A), lentejones equivalentes contienen fauna de conodontos del Ordovícico, Silúrico y Devónico (Rodríguez-Cañero,
1993; Martín-Algarra et al. 2009a; Rodríguez-Cañero et al. 2010). Estos lentejones calcáreos con conodontos y otros fósiles fueron inicialmente interpretados como olistolitos entre pelitas de las formaciones Santi Petri y/o Almogía (Herbig, 1984, 1985; Martín-Algarra, 1987). Sin embargo, nuevas y más precisas observaciones de campo realizadas dentro y fuera del área de estudio demuestran que estos niveles calcáreos forman parte de una sucesión pizarroso-areniscosa interestratificados con niveles de otras litologías, formando un conjunto típicamente maláguide que no encaja exactamente con ninguna de las unidades litoestratigráficas clásicas del Complejo mencionadas más arriba. La edad de dichos lentejones y, por tanto, de la sucesión siliciclástica que los alberga, está localmente bien establecida de acuerdo con las dataciones realizadas mediante conodontos, pero la sucesión en sí misma no está todavía bien caracterizada desde un punto de vista litoestratigráfico en su conjunto. En Cabrera-Porras et al. (2019), estos materiales se denominan "sucesión pre-Falcoña". 


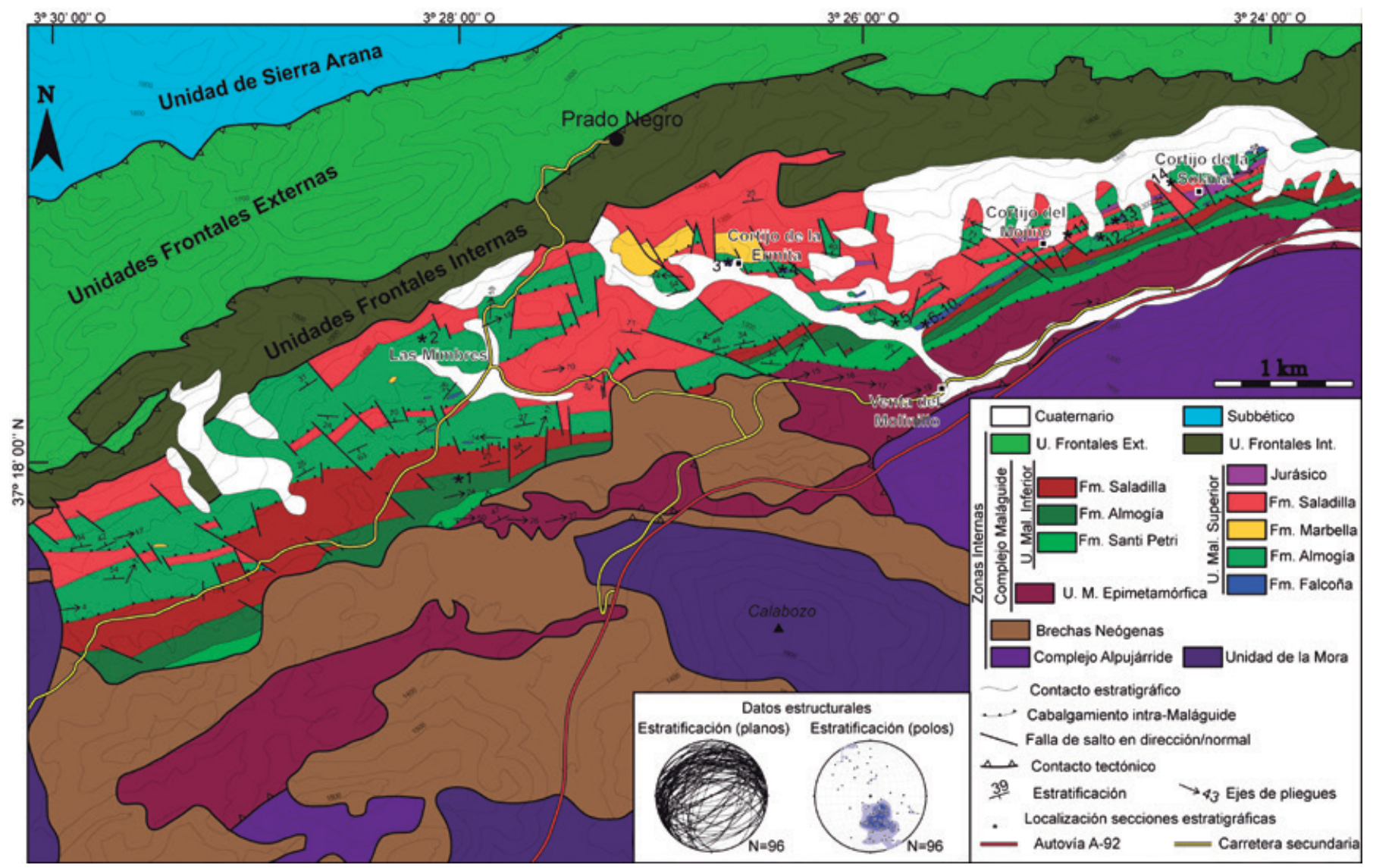

Figura 2. Cartografía del área de estudio. Confeccionada a partir de datos propios y otros modificados de Navarro-Vilá and García-Dueñas (1980), Sanz de Galdeano et al. (1995), Navas-Parejo (2012) y Rico-Colmenero (2015). Localización de los cortes estudiados (coordenadas geográficas): $1^{*}$ Loma Las Chorreras ( $\left.37^{\circ} 18^{\prime} 00^{\prime \prime} \mathrm{N}, 3^{\circ} 27^{\prime} 40^{\prime \prime} \mathrm{O}\right) ; 2^{*}$ Las Mimbres (37 $\left.18^{\prime} 01^{\prime \prime} \mathrm{N} 3^{\circ} 28^{\prime} 03^{\prime \prime} \mathrm{O}\right) ; 3^{*}$ Cortijo de la Ermita I ( $37^{\circ}$

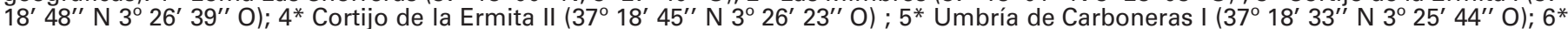

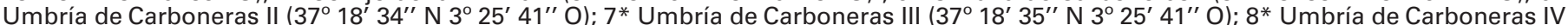

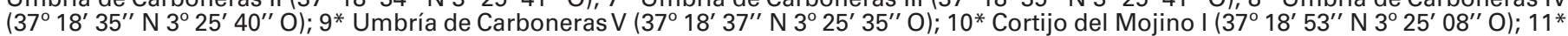

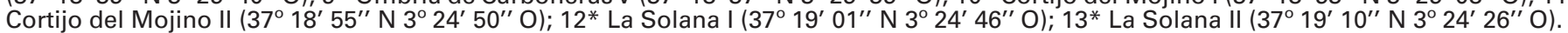

Figure 2. Map showing the distribution of the different lithologies in the study area. Made from own and modified cartographic data from Navarro-Vilá and García-Dueñas (1980); Sanz de Galdeano et al. (1995); Navas-Parejo (2012) and Rico-Colmenero (2015). Location of the

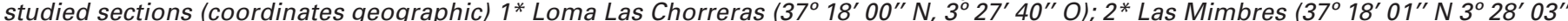

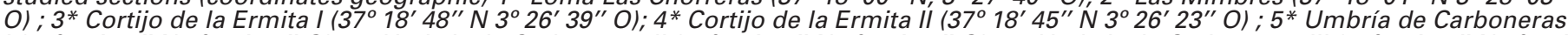

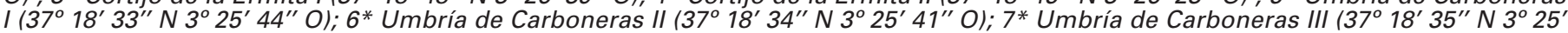

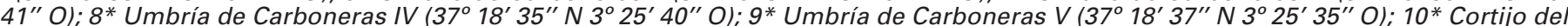

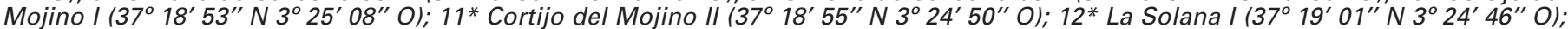
$13^{*}$ La Solana II $\left(37^{\circ} 19^{\prime} 10^{\prime \prime} N 3^{\circ} 24^{\prime} 26^{\prime \prime} O\right)$.

\section{Unidades tectónicas del Complejo Maláguide presen- tes en el área de estudio}

Desde un punto de vista estructural, el Complejo Maláguide aparece organizado en tres unidades tectónicas alpinas superpuestas, con estratigrafía y evolución térmica ligeramente diferentes (cf. Martín-Algarra, 1987; Navas-Parejo, 2012). Las unidades tectónicas han sido denominadas por los autores citados anteriormente como: Unidad Maláguide Epimetamórfica (UME), Unidad Maláguide Inferior (UMI) y Unidad Maláguide Superior (UMS) (Fig. 2). En estudios previos sobre el metamorfismo en esta zona, Ruiz Cruz et al. (2005) obtienen valores de Índice de cristalinidad de la Illita (IC) superiores a 0,42 , lo que equivale a temperaturas entre $50-200{ }^{\circ} \mathrm{C}$ (diagénesis) para el evento Alpino metamórfico en los materiales triásicos que ocupan una posición tectónica equivalente a las aquí denominadas UME y, posiblemente, UMI. Por otra parte, Ruiz Cruz and Sanz de Galdeano (2010) hallan unos valores de temperatura de aproximadamente $400{ }^{\circ} \mathrm{C}$ para el evento metamórfico pre-Alpino, que presenta un carácter uniforme en los materiales paleozoicos de ZCV. 


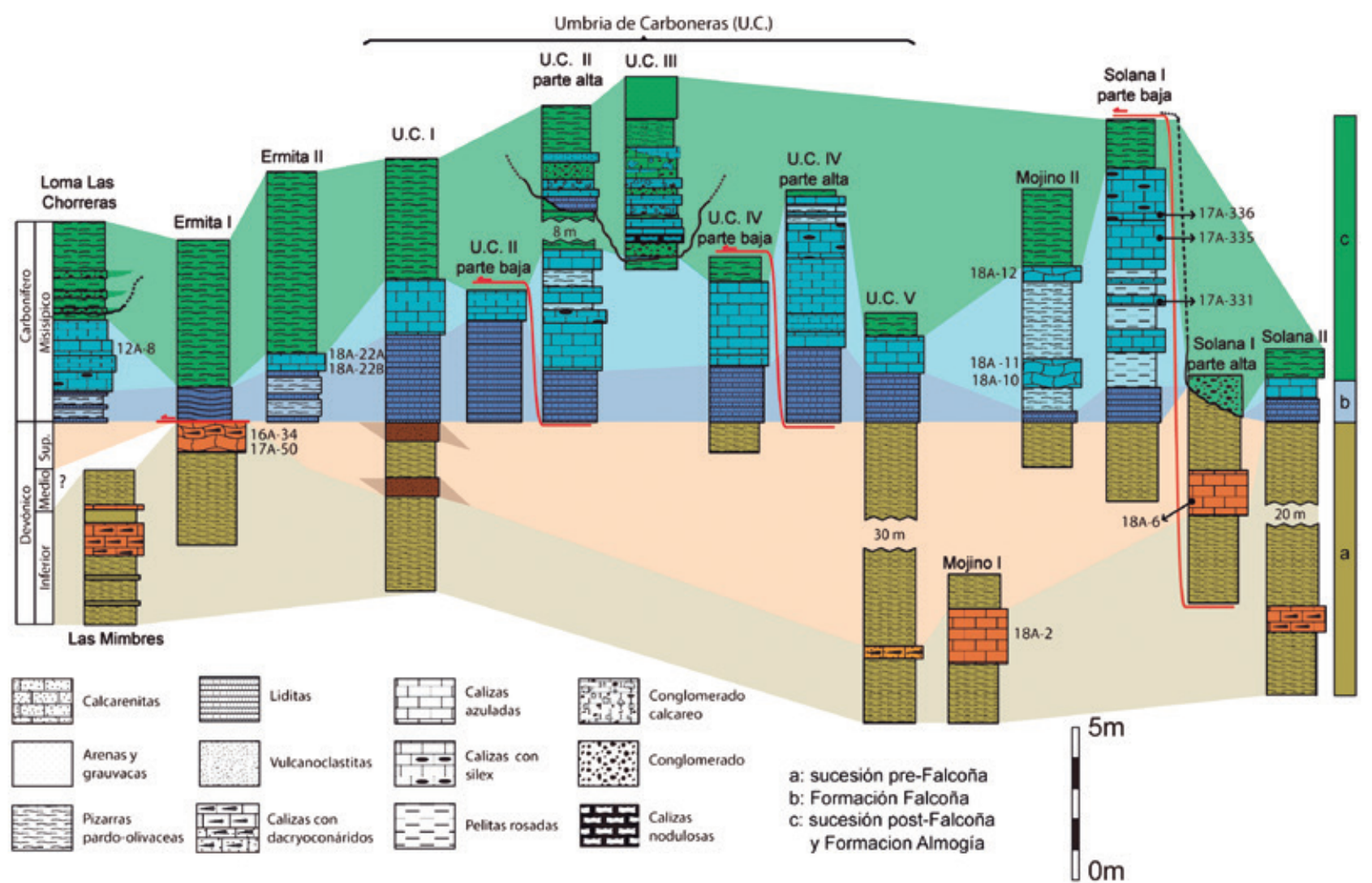

Figura 3. Correlación (WSW-ENE) entre las distintas secciones estratigráficas levantadas en la zona y la localización de las muestras tomadas en las diferentes secciones.

Figure 3: Correlation (WSW-ENE) between the different stratigraphic sections logged in the area and the location of the samples taken in the different sections.

\section{Unidad Maláguide Epimetamórfica (UME).}

Es la más baja y cercana al Complejo Alpujárride, y muestra rasgos transicionales a éste (Sanz de Galdeano et al. 1995). Está constituida por materiales triásicos afectados por un ligero metamorfismo (filitas, arcillitas, meta-arenitas y cuarcitas rojas) que se asignan a la Fm. Saladilla. Sobre ellos se sitúan unas dolomías negras con microfósiles, recubiertas en discordancia por brechas dolomíticas posiblemente de origen tectono-sedimentario y edad neógena. Finalmente, bajo las filitas rojas aparecen, localmente, pizarras satinadas y filitas pardas semejantes a la Fm. Almogía, que se atribuyen al Paleozoico. Esta unidad está localmente dividida en dos escamas.

\section{Unidad Maláguide Inferior (UMI).}

Su rasgo estratigráfico más característico es la presencia de la Fm. Santi Petri, que muestra sus facies típicas de calizas alabeadas alternando con pelitas pardo-oli- váceas, estas últimas más desarrolladas en la parte alta de la sucesión. Sobre ella, localmente, aparece la Fm. Falcoña, compuesta casi siempre por niveles lateralmente discontinuos y fuertemente replegados de liditas, ocasionalmente seguidos de calizas azuladas. La sucesión sigue con la Fm. Almogía, cuya existencia es difícil de asegurar a no ser que se constate la presencia en su base del Miembro Retamares. Sobre los materiales del Paleozoico se encuentra, discordantemente, la Fm. Saladilla.

\section{Unidad Maláguide Superior (UMS).}

Es la unidad mejor representada en la ZCV y la que se ha estudiado con mayor profundidad en este trabajo. Consta de materiales que van desde el Paleozoico hasta el Eoceno. Los materiales más antiguos están formados por pizarras y areniscas que intercalan niveles lateralmente discontinuos de rocas vulcanoclásticas y carbonatadas. El contenido fosilífero de estas últimas (conodontos y dacrioconáridos) indica una 


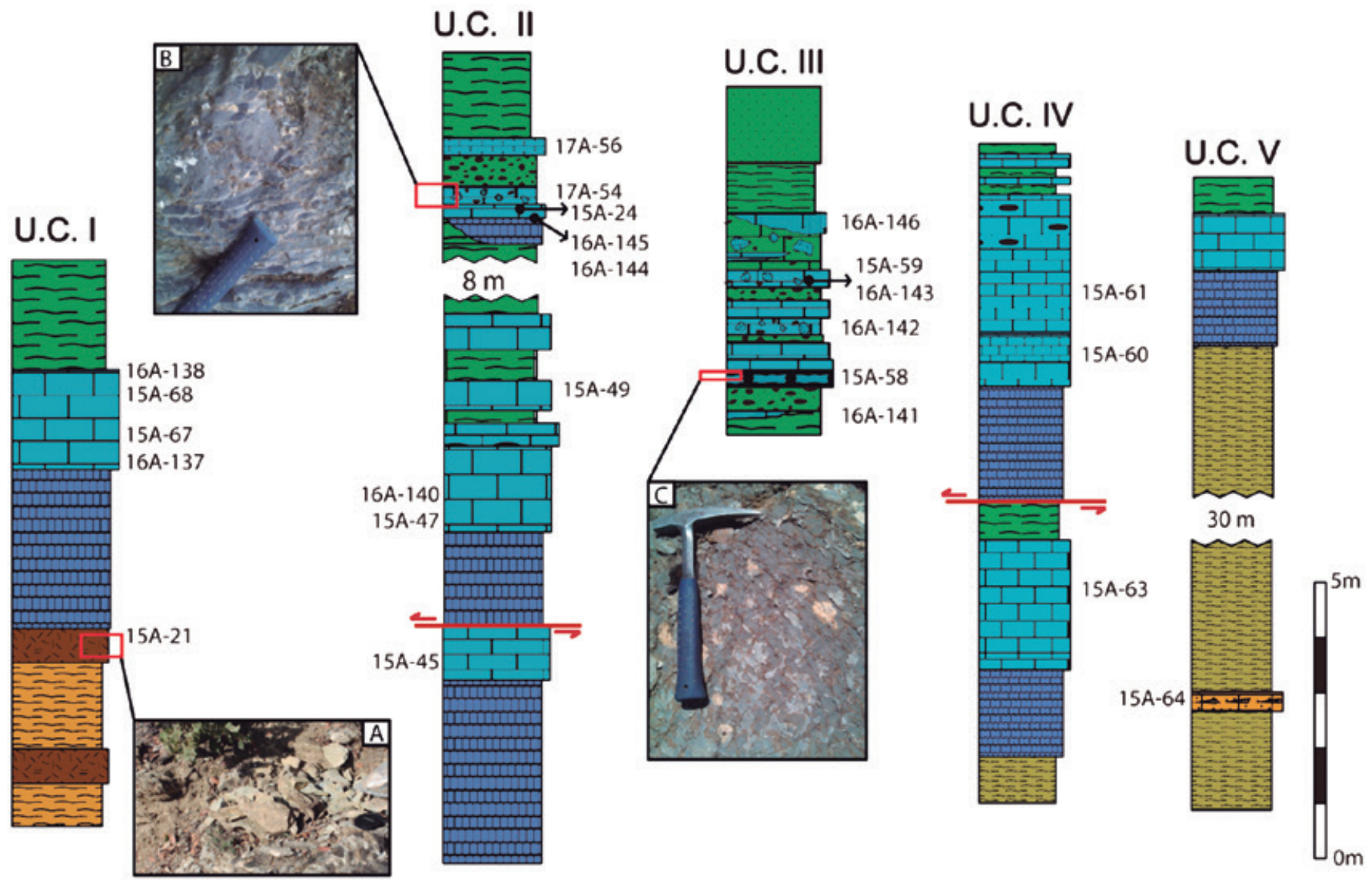

Figura 4. Secciones de la Umbría de Carboneras, con la localización detallada de las muestras que han dado resultados positivos en conodontos (leyenda litológica en la figura 3).

Figure 4. Umbria de Carboneras sections, with the detailed location of the samples that have given positive results for the conodonts (lithological legend in Figure 3).

edad Devónico. Este conjunto de materiales ha sido informalmente denominado sucesión pre-Falcoña por Cabrera-Porras et al. (2019).

La Fm. Falcoña, como es característico, está formada por radiolaritas negras (liditas) y calizas azuladas de edad Viseense superior-Serpukhoviense inferior (Navas-Parejo et al. 2015). Esta formación es lateralmente discontinua debido a la tectónica y a su poca potencia original.

En los nuevos cortes estudiados en el sector de la Umbría de Carboneras (Fig. 3) se constata que la Fm. Falcoña pasa, gradual y rápidamente hacia arriba, a la que se ha denominado sucesión post-Falcoña, dominada por pelitas que tradicionalmente han sido incluidas en la Fm. Almogía. En algunos de estos cortes aparecen uno o varios delgados horizontes lateralmente discontinuos de conglomerados con cantos calcáreos (en algún caso bloques) que, localmente, se disponen en discordancia erosiva sobre las calizas $\mathrm{Vi}$ seenses de la Fm. Falcoña.
Por encima de los niveles anteriores aparece la Fm. Almogía con sus típicas facies Culm.

EI Paleozoico de la UMS termina con la Fm. Marbella, separada de los terrenos subyacentes por un contacto erosivo (disconformidad). Aparece únicamente en las láminas cabalgantes superior e intermedia de las tres imbricaciones que se reconocen localmente en la UMS (Fig. 2).

La Fm. Saladilla incluye a los materiales triásicos de la zona, que destacan por su color rojizo. Son conglomerados en estratos de base canalizada, que se intercalan con y pasan lateral y gradualmente a areniscas, y éstas a lutitas.

Los materiales jurásicos se encuentran bien representados en la zona NE del mapa (sector del Cortijo de la Solana: Fig. 2). Forman una banda de poca potencia, pero de cierta continuidad. También se reconocen materiales del Eoceno, que no se han encontrado claramente in situ. 


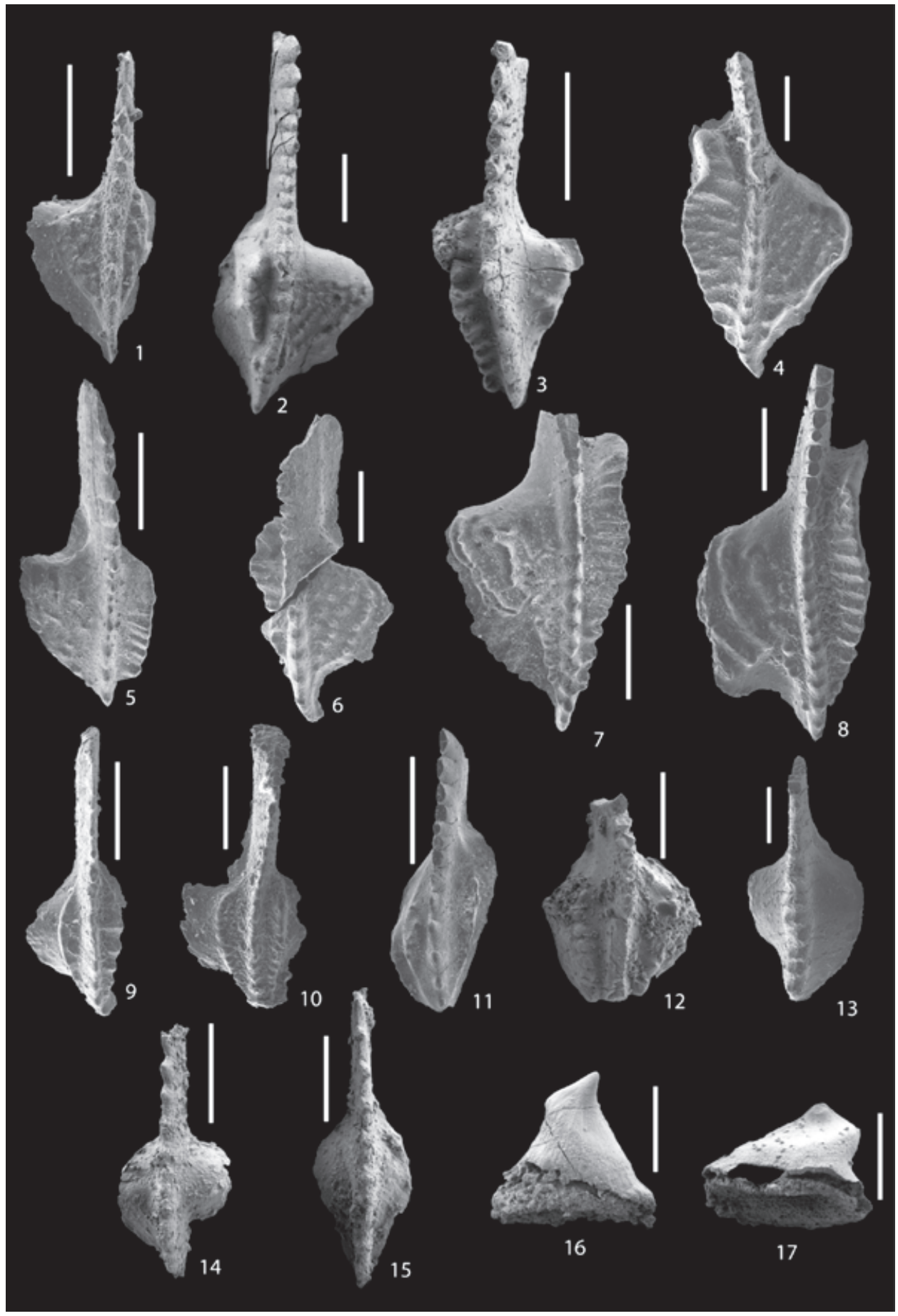

Figura 5. Conodontos de Zona de Cogollos Vega. 1: Gnathodus joseramoni (12A-18-1), vista oral. 2: Gnathodus joseramoni (12A-18-8), vista oral. 3: Gnathodus cf. praebilineatus (15A-68-1), vista oral. 4: Gnathodus bilineatus, vista oral (16A-144-1). 5: Gnathodus bilineatus bilineatus (16A-145-3), vista oral. 6: Gnathodus bilineatus (15A-24-1), vista oral. 7: Gnathodus bilineatus bilineatus (17A-54-1), vista oral. 8: Gnathodus bilineatus bilineatus (16A-146-1), vista oral. 9: Gnathodus girty meischneri (15A-24-3), vista oral. 10: Gnathodus girtyi girtyi (15A-58-6), vista oral. 11: Pseudognathodus homopunctatus (16A-142-2), vista oral. 12: Pseudognathodus homopunctatus (17A-335-1), vista oral. 13: Lochriea commutata (17A-56-1), vista oral. 14: Lochriea commutata (18A-12-1), vista oral. 15: Lochriea commutata (17A-331-1), vista oral. 16: Pseudooneotodus beckmanni (16A-134-1), vista lateral. 17: Pseudooneotodus beckmanni (18A-2-3), vista lateral. Escala: 200 $\mu$ m.

Figure 5. Conodonts of the Cogollos Vega Zone 1: Gnathodus joseramoni, (12A-18-1) oral view. 2: Gnathodus joserramoni, (12A-18-8) oral view. 3: Gnathodus cf. praebilineatus, (15A-68-1) oral view. 4: Gnathodus bilineatus (16A-144-1) oral view. 5: Gnathodus bilineatus (16A145-3) oral view. 6: Gnathodus bilineatus (15A-24-1) oral view. 7: Gnathodus bilineatus (17A-54-1) oral view. 8: Gnathodus bilineatus (16A 146-1) oral view. 9: Gnathodus girty meischneri (15A-24-3) oral view. 10: Gnathodus girty girty (15A-58-6) oral view. 11: Pseudognathodus homopunctatus (16A-142-2) oral view. 12: Pseudognathodus homopunctatus (17A-335-1) oral view. 13: Lochriea commutata (17A-56-1) vista oral 14: Lochriea commutata (18A-12-1) oral view. 15: Lochriea commutata (17A-331-1) oral view. 16: Pseudooneotodus beckmanni (16A-134-1) side view. 17: Pseudooneotodus beckmanni (18A-2-3) side view. Scale: $200 \mu \mathrm{m}$. 


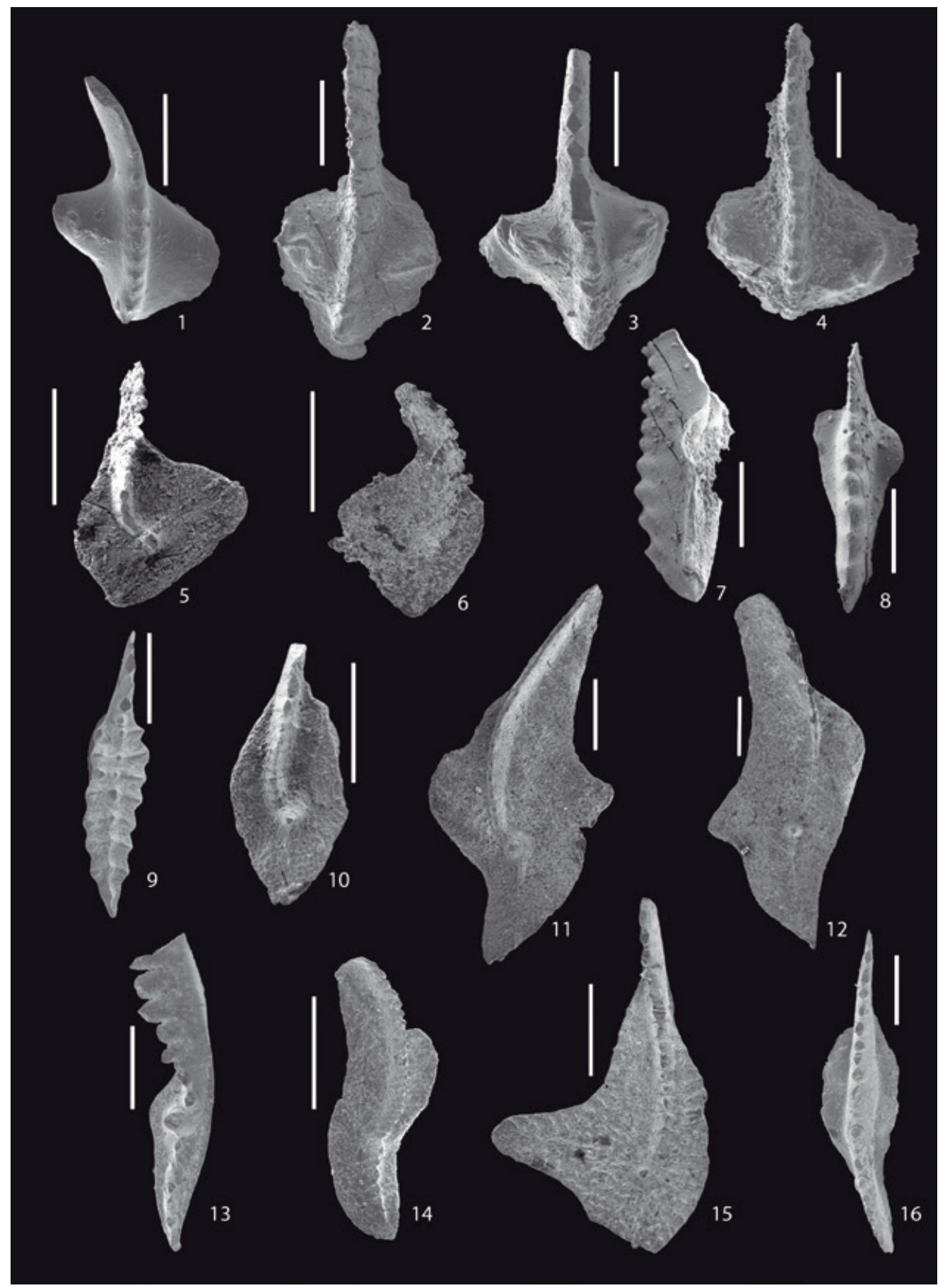

Figura 6. Conodontos de Zona de Cogollos Vega. 1: Lochriea monocostata, vista oral (16A-146-3). 2: Lochriea costata (15A-58-3), vista oral. 3: Lochriea ziegleri (15A-24-5), vista oral. 4: Lochriea ziegleri, vista oral (15A-58-5), vista oral. 5: Palmatolepis delicatula (18A-6-3), vista oral. 6: Palmatolepis delicatula (18A-6-4), vista oral. 7: Ozarkodina cf. bidentata (18A-2-5), vista lateral aboral. 8: Ozarkodina cf. bidentata (18A2-5), vista oral. 9: Alternognathus regularis (16A-142-3), vista oral. 10: Palmatolepis cf. regularis (18A-6-1), vista oral. 11: Palmatolepis tenuipunctata (16A-143-1), vista oral. 12: Palmatolepis tenuipunctata (15A-59-3), vista oral. 13: Palmatolepis gracilis gracilis (16A-143-4), vista oral. 14: Palmatolepis glabra pectinata (17A-54-2), vista oral. 15: Palmatolepis triangularis (16A-142-1), vista oral. 16: Bispathodus stabilis (16A-143-3), vista oral. Escala: $200 \mu \mathrm{m}$.

Figure 6. Conodonts of the Cogollos Vega Zone. 1: Lochriea monocostata (16A-146-3) oral view. 2: Lochriea costata (15A-58-3) oral view. 3: Lochriea ziegleri (15A-24-5) oral view. 4: Lochriea ziegleri (15A-58-5) oral view. 5: Palmatolepis delicatula (18A-6-3) oral view. 6: Palmatolepis delicatula, (18A-6-4) oral view. 7: Ozarkodina cf bidentata (18A-2-1) side view. 8: Ozarkodina cf. bidentata (18A-2-5) oral view. 9: Alternognathus regularis (16A-142-3), oral view. 10: Palmatolepis cf. regularis (18A-6-1), oral view. 11: Palmatolepis tenuipunctata (16A-143-1) oral view. 12: Palmatolepis tenuipunctata (15A-59-3) oral view. 13: Palmatolepis gracilis gracilis (16A-143-4) oral view. 14: Palmatolepis glabra pectinata (17A-54-2) oral view. 15: Palmatolepis triangularis (16A-142-1) oral view. Scale: 200 um. 16: Bispathodus stabilis (16A-1433), oral view. Scale: $200 \mu \mathrm{m}$. 


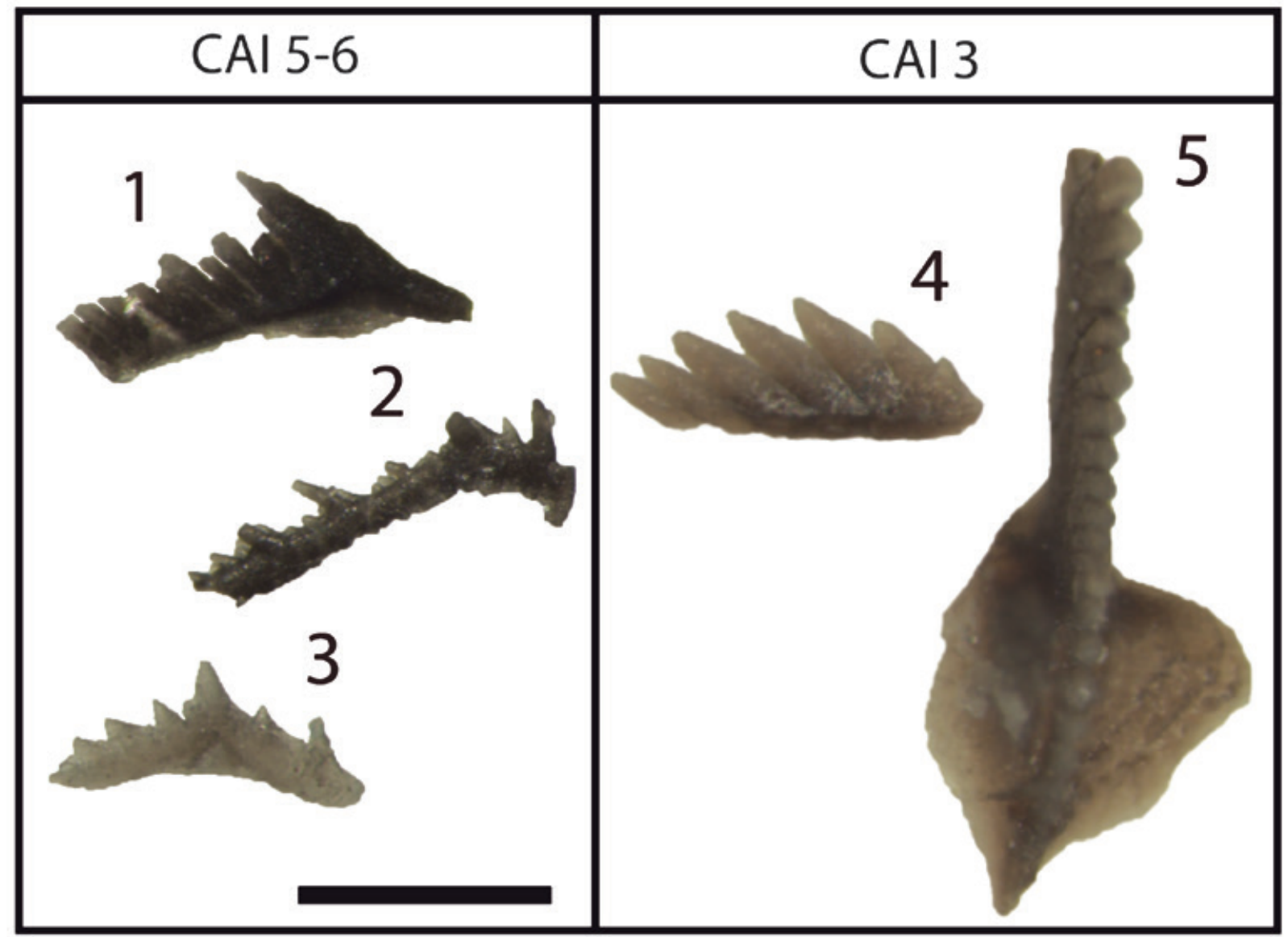

Figura 7. Elementos conodontales fotografiados con lupa binocular para la identificación del CAI. 1: S indet., CAI: 5 (18A-2). 2: S, CAI: 5,5 (15A-60). 3: S, CAl: 6 (15A-67). 4: S, CAl: 3 (12A-18). 5: P, Gnathodus joseramoni, CAl:3 (12A-18). Escala: $500 \mu \mathrm{m}$.

Figure 7. Conodont elements photographed with binocular magnifying glass for the identification of CAI. 1: $S$ indet., CAl: 5 (18A-2). 2: $S$, CAl: 5.5 (15A-60). 3: S, CAl: 6 (15A-67). 4: S, CAl: 3 (12A-18). 5: P, Gnathodus joseramoni, CAl: 3 (12A-18). Scale: 500 rm.

\section{Metodología}

\section{Trabajo de campo: cartografía, cortes, columnas y muestreo}

Se ha realizado una cartografía de la zona estudiada a escala 1:10.000, donde se ha precisado la litoestratigrafía y bioestratigrafía (Fig. 2). Se han estudiado un total de once afloramientos (Loma de las Chorreras, Cortijo de la Ermita I, Cortijo de la Ermita II, Umbría de Carboneras I, Umbría de Carboneras II, Umbría de Carboneras III, Umbría de Carboneras IV, Umbría de Carboneras V y Cortijo del Mojino I, Cortijo del Mojino II y La Solana II) y revisado otros tres que han sido objeto de publicaciones previas (Las Mimbres, Corte al norte de la Umbría de Carboneras, La Solana I), y se han dibujado a escala las columnas estratigráficas de detalle (Figs. 3 y 4). Todos ellos han sido localizados telemáticamente mediante la aplicación Locus Map Free-Outdoor GPS (Fig. 2). En dichos afloramientos se han tomado un total de 55 muestras, de entre 1 y $1,5 \mathrm{Kg}$ cada una, para estudios de conodontos, de las cuales 35 han resultado productivas (Tabla 1), y 6 para el estudio de las vulcanoclastitas. De todas ellas se han realizado láminas delgadas para el estudio petrográfico, y finalmente, se han tomado medidas con la brújula de la orientación de la estratificación y de las estructuras tectónicas.

\section{Trabajo de laboratorio y gabinete}

Para la extracción de los elementos conodontales se han disuelto las muestras de calizas siguiendo el método propuesto por Jeppsson et al. (1999) y se ha tamizado el residuo insoluble obtenido usando dos tamices de 0,50 $\mathrm{mm}$ y 0,16 $\mathrm{mm}$ de luz de malla. Dicho residuo se ha concentrado, utilizando metatungstato de sodio, siguiendo el protocolo propuesto por Anderson et al. (1995). Posteriormente, se ha efectuado el triado bajo 


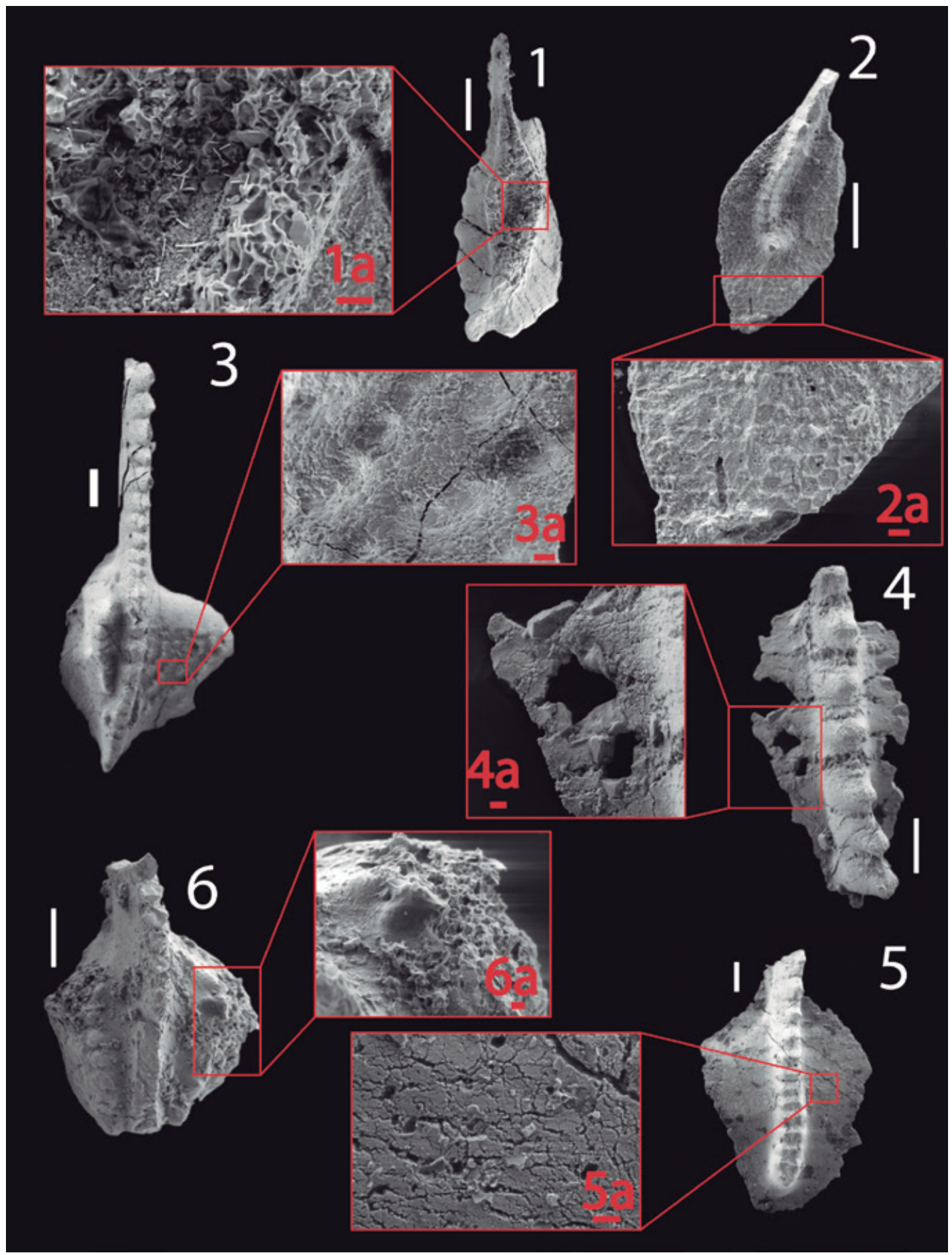

Figura 8. Microtexturas de diferentes elementos conodontales. 1: $P_{1}$, Polygnathus sp. (18A-2) con CAI 5, superficie aboral 1a: microtexturas de recubrimiento irregular en la cavidad basal. 2: $P$ de Palmatolepis cf. regularis (18A-6) con CAI 5. 2a: microtextura en la superficie oral con patrón poligonal original. 3: $\mathrm{P}$ Gnathodus joseramoni $(12 \mathrm{~A}-18)$ con CAl 3, 3a: microtextura de sobrecrecimiento diagenético. 4: $\mathrm{P}$ de Locriea sp. (15A-60) con CAI 5.5, 4a: microtextura de disolución y cristales autigénicos. 5: $P_{1}$ de Lochriea commutata (17A-335) con CAI 5.5 5a: microtextura de disolución y recristalización de pequeños cristales irregulares. 6: Elemento $\mathrm{P}$, de Pseudognathodus homopunctatus (17A-335) con CAI 5.5, 6a: microtexturas de recubrimiento irregular. Escala (barra blanca): $100 \mu \mathrm{m}$; barra roja: $10 \mu \mathrm{m}$.

Figure 8. Microtextures found in different conodont elements. 1: $P$, Polygnathus (18A-2) with CAI 5, 1a: irregular microtextures covering the basal cavity. 2: $P$, Palmatolepis cf. regularis $(18 A-6)$ with CAI 5, 2a: microtextures with original polygonal pattern in the oral surface. 3: $P$, Gnathodus joseramoni (12A-18) with CAl 3, 3a: diagenetic overgrowth microtexture. 4: $P$, Locriea sp. (15A-60) with CAl 5.5. 4a: dissolution microtexture and authigenic crystals. 5: $P$, Lochriea commutata, (17A-335) with CAI 5.5, ${ }^{1}$ 5a: dissolution microtexture and recrystallization of small irregular crystals. 6: Element $P$, Pseudognathodus homopunctatus (17A-335) with CAl 5.5, 6a: irregular coating microtextures. Scale (white bar): $100 \mu \mathrm{m}$; (red bar): $10 \mu \mathrm{m}$. 
la lupa binocular para la recolección de los elementos conodontales. Los ejemplares mejor conservados se han fotografiado con el microscopio electrónico de barrido GEMINI (FESEM) CARL ZEISS. Asimismo, se han tomado algunas fotografías con un microscopio LeicaM205C provisto de una cámara Leica MC170HD, de aquellos ejemplares cuyo color se ha considerado útil para ilustrar el estudio del CAI. La determinación de los valores de CAl de los elementos conodontales se ha realizado utilizando dos procedimientos: la comparación con una escala de CAl estándar y con las tablas Munsell, según la escala de color que establecieron Epstein et al. (1977) y Rejebian et al. (1987). Utilizando también el microscopio electrónico de barrido se ha hecho una primera aproximación al estudio microtextural de los elementos siguiendo a Sanz-López and Blanco-Ferrera (2012) y un análisis de ciertos cristales mediante difracción de electrones (EDX).

\section{Resultados}

\section{Cortes estudiados y bioestratigrafía mediante cono- dontos}

La localización de los cortes estudiados está indicada en la Figura 2. La fauna de conodontos hallada en cada uno de ellos se recoge en la Tabla 1.

Loma las Chorreras (Fig. $2 * 1$; Fig. 3). Su base está formada por un delgado nivel laminado de liditas y pelitas, de un metro de espesor y sobre ellas descansa un paquete de calizas, de unos 2 metros, integrado en la base por gruesos estratos con sílex y por calizas azuladas hacia techo, todos estos materiales pertenecen a la Fm. Falcoña. La sección finaliza con unas pelitas oliváceas que alternan con grauvacas micáceas en estratos con base erosiva, de la Fm. Almogía. La muestra 12A-18, tomada en el nivel de las calizas azuladas, ha proporcionado Gnathodus sp. G. joseramoni y Lochriea commutata, por lo que se ha atribuido al Viseense superior

Las Mimbres (Fig. $2 * 2$; Fig. 3). Este corte ya fue descrito por Navas-Parejo et al. (2011), en él hallaron Criteriognathus steinhornensis y Pseudooneotodus beckmanniy lo atribuyeron al Emsiense (Devónico Inferior). Se trata de una serie pizarrosa en la que se intercala un nivel de calizas tableadas que lateralmente se unen para formar un estrato más compacto, de un metro de potencia, con dacrioconáridos y conodontos; estos materiales forman parte de lo que aquí denominamos como sucesión pre-Falcoña.

Cortijo de la Ermita I (Fig. 2 *3; Fig. 3). El corte comienza con un gran paquete de pizarras pardo-oliváceas que relacionamos con la sucesión pre-Falcoña, seguido por un nivel calcáreo tableado de un metro de espesor aproximadamente, con dacrioconáridos y, sobre él, un paquete de liditas de 1,2 metros de potencia máxima y asignables al miembro inferior de la Fm. Falcoña, ambos muy replegados y tectónicamente laminados en varios puntos. Sobre estos niveles aparece un paquete de pizarras oliváceas bien estratificadas. La muestra 16A-134 tomada en un estrato del nivel calcáreo tableado ha proporcionado Pseudooneotodus beckmanni. La presencia de Ps. beckmanni y los dacrioconáridos permite asignar estos niveles al Devónico Inferior.

Cortijo de la Ermita II (Fig. $2 * 4$; Fig. 3). La sección se inicia con una alternancia de liditas y pizarras de 1,5 metros de espesor $y$, sobre ellas, aparece un nivel tableado de calizas azuladas de 0,5 metros de potencia; la muestra 18A-22B tomada en dicho nivel ha proporcionado ejemplares de Gnathodus mal conservados, que no permiten su identificación a nivel específico pero que confirman que el corte pertenece a la $\mathrm{Fm}$. Falcoña. A techo termina con un paquete de pizarras oliváceas, pertenecientes a la Fm. Almogía.

Umbría de Carboneras I (UC-I) (Fig. 2 *5; Figs. 3 y 4). La base del corte la forma un paquete de pizarras y areniscas bien estratificadas entre las que se intercalan dos niveles de vulcanoclastitas de medio metro de espesor (Fig. 4: UC-I y Foto A); sobre el más alto, se encuentra un paquete de liditas de unos $3 \mathrm{~m}$, al que siguen $2 \mathrm{~m}$ de calizas azuladas, ambas litologías pertenecientes a la Fm. Falcoña, que pasan a pizarras oliváceas mediante un contacto neto (Fm. Almogía). A lo largo del paquete de calizas se han tomado cuatro muestras (16A-137, 15A-67, 15A-68, y 16A-138) que han librado ejemplares de Gnathodus joseramoni y $G$. cf. praebilineatus, así como otros elementos $P_{1}$ de Gnathodus mal conservados, que no permiten una determinación específica. En conjunto los niveles se datan como Viseense superior

Umbría de Carboneras II (UC-II) (Fig. $2 * 6$; Figs. 3 y 4). La parte baja de este corte (UC-II-parte baja), contiene un paquete de liditas de unos $5 \mathrm{~m}$ de espesor y, sobre éstas, unas calizas azuladas de $1 \mathrm{~m}$, ambos asignables a la Fm. Falcoña. En la parte inferior del tramo calizo se tomó la muestra 15A-45 que ha proporcionado algunos elementos $\mathrm{P}_{1}$ de Gnathodus mal conservados, lo que no permite ninguna precisión bioestratigráfica. En la parte alta del corte (UCII-parte alta) se observa una repetición tectónica de la misma sucesión, pero con menor potencia de liditas y mayor potencia de calizas. En los niveles inferiores del paquete calizo se han tomado las muestras 15A-47 y $16 A-140$, en una posición equivalente a la muestra 15A-45, que solo han liberado unos fragmentos de elementos ramiformes. Dicho paquete calizo finaliza con algunos estratos finos de calizas con sílex y ca- 


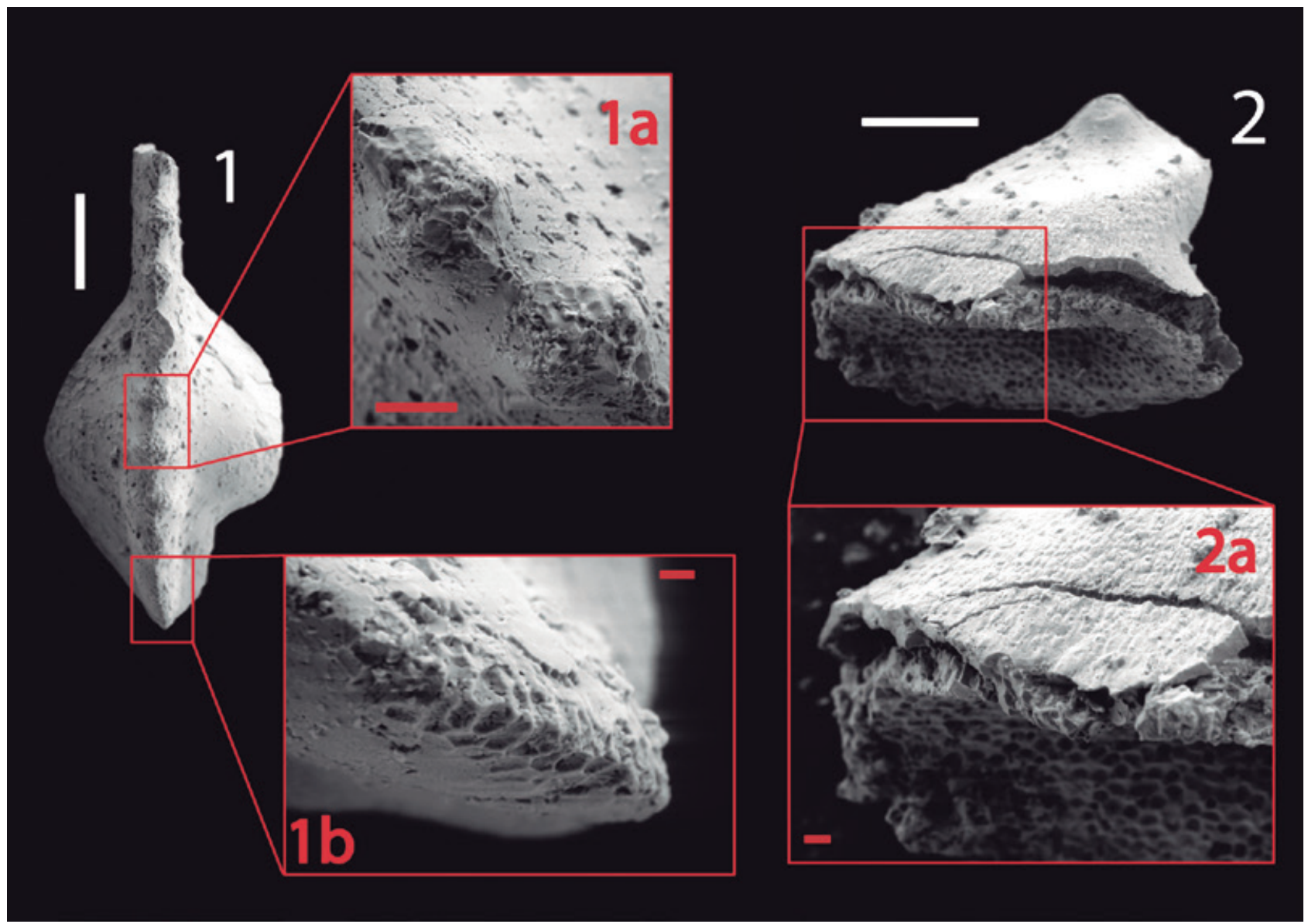

Figura 9. Detalle de la ornamentación de diferentes elementos conodontales. 1: $P_{1}$, Lochriea, commutata (17A-336-1). 1a y 1b: micrornamentación primaria, red poligonal 2: Elemento coniforme, Pseudooneotodus beckmanni (18A-2-3). 2a: cuerpo basal y corona donde se observan las diferencias texturales de ambos. Escala (barra blanca) $100 \mu \mathrm{m}$, (barra roja): $10 \mu \mathrm{m}$

Figure 9. Detail of the ornamentation recognized in the different conodont elements. 1: $P_{1}$, Lochriea commutata (17A-336). 1a and 1b: primary microornamentation, polygonal network. 2: Coniform element, Pseudooneotodus beckmanni (18A-2). 2a: basal body and crown where the textural differences of both are observed. Scale (white bar): $100 \mu \mathrm{m}$, (red bar): $10 \mu \mathrm{m}$.

lizas azuladas, que pasan a un paquete de pizarras oliváceas, seguido por grauvacas algo calcáreas. De las calizas azuladas procede la muestra $15 \mathrm{~A}-49$ que ha suministrado elementos $\mathrm{P}_{1}$ de Gnathodus bilineatus, G. sp. y algunos ramiformes. Sobre estas últimas pizarras y grauvacas, siguiendo el mismo lecho del barranco y mediando una pequeña falla, aparece un conglomerado calcáreo que incluye cantos de calizas, algunos de dimensiones decimétricas, que se corresponden con fragmentos de estratos tableados. De este conglomerado "post-Falcoña" se tomaron un total de cinco muestras correspondientes a cinco clastos diferentes que han suministrado la fauna de conodontos que se indica a continuación: muestras $16 \mathrm{~A}-144$ y $16 \mathrm{~A}$ 145: Lochriea commutata y Gnathodus bilineatus que indican una edad Viseense superior- Serpukhoviense inferior; muestra 15A-24: Lochriea commutata, L. ziegleri, Gnathodus bilineatus y Gnathodus girtyi, del Serpukhoviense inferior; muestra 17A-54: Palmatole- pis glabra prima, Palmatolepis sp., Gnathodus bilineatus y Gnathodus sp., en la que se detecta una mezcla de fauna del Fameniense (Devónico Superior) y del Carbonífero Inferior; y por último la muestra 17A-56, que ha proporcionado Lochriea commutata, Gnathodus bilineatus, Gnathodus sp. y Pseudognathodus homopunctatus que correspondería a un Viseense superior.- Serpukhoviense inferior.

Umbría de Carboneras III (UC-III) (Fig. $2 * 7$; Figs. 3 y 4). Este corte es bastante similar al UC-II-parte alta y se sitúa a pocos metros hacia el este. La principal diferencia estriba en que en su base aparece un nivel de calizas nodulosas (Fig. 4, C), de unos decímetros de espesor y poco más de un metro de continuidad lateral, que se intercala entre delgados niveles de conglomerados con cantos calizos y otros centimétricos de cuarcita. En la parte inferior se ha muestreado un nivel calizo (muestra 16A-141) en la que sólo se ha hallado un Gnathodus sp., y, procedente del nivel de calizas 
nodulosas, la muestra $15 \mathrm{~A}-58$ ha suministrado elementos de Gnathodus girtyi, Gnathodus sp., Lochriea costata, Lo. monocostata y Lo. ziegleri; que permiten asignar este nivel al Serpukhoviense inferior. Las cuatro muestras de cantos calizos del conglomerado han suministrado la siguiente fauna: en la muestra 16A142 hay una mezcla de fauna del Carbonífero Inferior y del Devónico Superior: Gnathodus sp., Pseudognathodus homopunctatus, Palmatolepis triangularis, Alternognathus regularis y Polygnathus sp.; la muestra 15A-59 con Palmatolepis gracilis gracilis y $\mathrm{Pa}$. tenuipunctata, y la 16A-143 con Palmatolepis gracilis gracilis, Pa. tenuipunctata y Bispathodus stabilis, indica la presencia de un Fameniense (Devónico Superior); por último, la muestra 16A-146, contiene Gnathodus bilineatus, Gnathodus sp. y Lochriea monocostata, que datan un Viseense superior-Serpukhoviense inferior.

Umbría de Carboneras IV (UC-IV) (Fig. $2 * 8$; Figs. 3y 4). Este corte es semejante al corte UC-II y, al igual que aquél, se divide en dos partes separadas por un contacto tectónico. La parte baja (UC-IV parte baja) está formada por pelitas, sobre las que se halla un paquete de liditas y calizas de la Fm. Falcoña, con pizarras a techo. En el nivel calizo la muestra $15 \mathrm{~A}-63$ solo ha suministrado fragmentos de elementos ramiformes y las muestras $15 \mathrm{~A}-60$ y $15 \mathrm{~A}-61$ con Gnathodus bilineatus, Lochriea commutata y Gnathodus sp., se atribuyen al Viseense superior- Serpukhoviense más bajo. En la parte alta (UC-IV parte alta) se repite la misma sucesión reconocida en la parte baja, con mayor potencia en las calizas que, hacia techo, incluyen niveles con sílex y culminan con calizas tableadas. Más arriba, aparecen pelitas, grauvacas y niveles de conglomerados con cantos calcáreos "post-Falcoña", semejantes a los del corte anteriory algo peor expuestos.

Umbría de Carboneras V (UC-V) (Fig. $2 * 9$; Figs. 3 y 4). La presencia, en la base de este corte, de unas calcarenitas con dacrioconáridos, entre un paquete de pizarras de más de 30 metros de espesor, permite atribuirlo al Devónico. A techo, el corte termina con liditas y calizas azuladas de la Fm. Falcoña, seguidas de pizarras oliváceas "post-Falcoña" en una sucesión semejante a los tres cortes anteriores. Entre las pizarras inferiores "pre-Falcoña" aparecen intercalaciones de vulcanoclastitas cada vez más desarrolladas hacia el Este.

Cortijo del Mojino I (Fig. $2 * 10 ;$ Fig. 3). En esta sección aparece un nivel calizo intercalado entre pelitas. La muestra 18A-2, procedente de la parte alta de este nivel, ha proporcionado ejemplares de Pseudooneotodus beckmanni, Ozarkodina cf. bidentata y Polygnathus sp. La edad de este nivel es incierta puesto que Ps. beckmanni se extiende hasta el Devónico Inferior, mientras que Ozarkodina bidentata es del Devónico
Medio. Teniendo en cuenta que la determinación de $O$. bidentata no es segura, no se asigna edad a este nivel hasta que se haga una posterior investigación.

Cortijo del Mojino II (Fig. $2 * 11$; Fig. 3). En esta otra sección afloran dos niveles de calizas azuladas entre una sucesión de pelitas, a cuya base aparecen liditas pertenecientes a la $\mathrm{Fm}$. Falcoña y a techo pizarras. La muestra 18A-10 ha proporcionado ejemplares de Gnathodus bilineatus, Gnathodus sp. y Lochriea commutata. La 18A-11 Gnathodus bilineatus y Gnathodus sp. y 18A-12 Lochriea commutata. La presencia de Gnathodus bilineatus y Lochriea commutata permite asignar a estos niveles una edad comprendida en el intervalo Viseense superior-Serpukhoviense inferior.

La Solana I-parte baja (Fig. $2 * 12$; Fig. 3). Este corte fue descrito por Navas-Parejo et al. (2015) como "sucesión sur", cuya parte alta asignaron a la Fm. Falcoña. En el nivel calizo estos autores, obtuvieron Gnathodus bilineatus romulusy lo atribuyeron al intervalo comprendido entre la Zona de bilineatus y la Zona de ziegleri (Viseense-Serpukhoviese). Esta parte del corte está formada por una sucesión semejante a la descrita en los cortes previos: unas pizarras "pre-Falcoña" a la base, sobre las que se encuentra la Fm. Falcoña, integrada por liditas y calizas que, en sus niveles más altos, contienen nódulos de sílex y entre las que se intercalan lechos de pelitas rosadas y violáceas. La sucesión finaliza con unas pizarras oliváceas "post-Falcoña". En este trabajo se tomaron cinco muestras de los anteriormente citados niveles calizos, de las cuales tres han suministrado fauna de conodontos: las muestras 17A-331 y 17A-336 han liberado ejemplares de Lochriea commutata; y la 17A-335 ejemplares de Gnathodus bilineatus, Lochriea commutata y Pseudognathodus homopunctatus lo que permite atribuir estos niveles al Viseense superior-Serpukhoviense inferior.

La Solana I - parte alta (Fig. $2 * 12$; Fig. 3). En esta sección se encuentra un nivel carbonatado de un metro y medio de potencia, entre pelitas a la base y pizarras a techo, sobre el que aparece un paquete de pelitas seguido de un estrato muy grueso de conglomerados con una manifiesta base erosiva. Este corte también fue descrito por Navas-Parejo et al. (2015) denominándolo "sucesión norte". En tres muestras de los niveles calizos obtuvieron ejemplares de Palmatolepis angularis, Pa. crepida, Pa. quadrantinodosalobata, Pa. cf. regularis, Pa. tenuipunctata e Icriodus alternatus alternatus que atribuyeron a las biozonas superior y más superior de crepida (Fameniese, Devónico Superior). Asimismo, estos autores asignaron el conglomerado de base erosiva al Miembro Retamares de la Fm. Almogía, ya que incluye clastos de liditas de la Fm. Falcoña. En el paquete de calizas se ha toma- 
do la muestra 18A-6 que ha proporcionado elementos de Palmatolepis cf. regularis y Pa. delicatula, que permiten atribuir estos niveles al Fameniense (Devónico Superior)

La Solana II (Fig. $2 * 13$; Fig. 3). En la base de este corte aparece un banco de calizas con dacrioconáridos (Devónico), de algo menos de un metro de espesor, intercalado entre pizarras. A techo, varios metros más arriba y sobre un tramo de pizarras mal expuestas, aparecen liditas y calizas azuladas que, por su posición y litofacies, se han asignado a la Fm. Falcoña, aunque no han suministrado fauna de conodontos.

\section{Taxonomía}

A continuación, se describen someramente los caracteres morfológicos diagnósticos de los elementos $P_{1}$ de las diferentes especies de conodontos del Devónico y del Carbonífero que se han hallado en los afloramientos estudiados de la ZCV. Para indicar la posición de los elementos conodontales en el aparato, así como su orientación anatómica, se ha utilizado la notación biológica establecida por Purnell et al. (2000); para la denominación de los elementos como un todo atendiendo a su morfología, la propuesta por Sweet (1988); y, para la descripción de sus elementos morfológicos, las propuestas por García-López (1984), Rodríguez-Cañero (1993) y Bermúdez Rochas (2003). Las especies halladas en las diferentes muestras se recogen en laTabla 1.

Filo Chordata Haeckel, 1874

Clase Conodonta Pander, 1856

Orden Ozarkodinida Dzik, 1976

Familia Cavusgnathidae Austin and Rhodes, 1981

Género Alternognathus Ziegler and Sandberg, 1984

Alternognathus regularis Ziegler and Sandberg, 1984 Fig. 6: 9

El elemento $P_{1}$ de esta especie se caracteriza por poseer una plataforma lanceolada, adornada con pequeñas costillas/nódulos alargados dispuestos perpendicularmente a la carena, que está formada por nódulos separados, pero unidos hacia su parte dorsal por una ligera cresta. Su lámina libre está constituida por dentículos unidos y tiene una longitud equivalente a un tercio de su longitud total, además de presentar mayor altura en su parte ventral. La cavidad basal es estrecha y alargada y se sitúa en la parte ventral de la plataforma. Hartenfels (2010) diferenció dos subespecies atendiendo a que la carena presente una pequeña interrupción antes de la lámina libre: $A$. regularis regu- laris; o no lo haga: A. regularis continuus; el ejemplar aquí hallado (16A-142-3, Fig. 6:10), se correspondería con esta segunda subespecie.

Distribución estratigráfica: Zona más alta de marginifera- zona superior de postera (Ziegler and Sandberg, 1984; Perri and Spalletta, 1998)

\section{Familia Gnathodontidae Sweet, 1988}

Género Gnathodus Pander, 1856

El elemento $\mathrm{P}_{1}$ de Gnathodus es pectiniforme carminiescafado.

\section{Gnathodus bilineatus (Roundy, 1926)}

Fig. 5: 4-8

El elemento $\mathrm{P}_{1}$ de Gnathodus bilineatus, se caracteriza por presentar un parapeto caudal largo y bien desarrollado que alcanza el extremo dorsal de la plataforma, cuya parte rostral se halla ornamentada con tubérculos y/o costillas. En función del desarrollo, la morfología del parapeto caudal, el contorno y la ornamentación de la plataforma rostral, diferentes autores han definido un número importante de subespecies. Los ejemplares: $16 \mathrm{~A}-145-3$ y $15 \mathrm{~A}-24-1$, Fig. 5 : 7 y 8, pertenecen a la subespecie $G$. bilineatus bilineatus (Roundy, 1926) dada la profunda ornamentación con costillas y nódulos que presenta su plataforma rostral $y$, sobre todo, por la presencia de la pequeña y característica fila de nódulos adyacentes a la carena en su parte dorso-rostral.

Distribución estratigráfica: Viseense superiorBashkiriense inferior (Blanco-Ferrera et al. 2005).

\section{Gnathodus girtyi Hass, 1953}

Fig. 5: 9 y 10

El elemento $P_{1}$ presenta una plataforma alargada, un poco más ancha en su parte ventral y puntiaguda en su parte dorsal, con dos parapetos que discurren paralelos a ambos lados de la carena, siendo el caudal más alto y normalmente más desarrollado que el rostral. La cavidad basal presenta expansiones, siendo más amplia la parte rostral. El ejemplar 15A-24-3 (Fig. 5: 9) se incluye en la subespecie G. girtyi meischneri Austin and Husri, 1974, atendiendo a que presenta un parapeto rostral liso a modo de costilla paralela a la carena, que comienza más dorsalmente que el caudal y no alcanza el extremo dorsal. Y el ejemplar 15A58-6 (Fig. 5: 10) se incluiría en la subespecie G. girtyi girtyi Hass, 1953 ya que presenta dos parapetos bien desarrollados y ornamentados con pequeñas crestas, el rostral comienza más dorsalmente que el caudal y ambos alcanzan el extremo dorsal donde se unen a la 
carena llegando a formar pequeñas crestas transversales

Distribución estratigráfica: Viseense superior

- Serpukhoviense inferior (Nemyrovska and Samankassou, 2005).

\section{Gnathodus joseramoni Sanz-López, Blanco-Ferrera and García-López, 2004}

Fig. 5: 1 y 2

El elemento $P_{1}$ se caracteriza por poseer un parapeto corto situado hacia la parte ventral de la plataforma caudal. Este parapeto suele estar formado por nódulos o pequeñas crestas. La plataforma rostral es triangular con la parte más ancha en su extremo ventral y, sobre ella, se desarrollan nódulos que, en la mayoría de los elementos, están dispuestos en filas concéntricas. La carena tiende a ensancharse en su extremo dorsal. El ejemplar 12A-8-2 es muy pequeño y no ha llegado a desarrollar totalmente estas características (Fig. 5: 1), que sí las muestra el ejemplar 12A-18, que es más maduro y de mayor tamaño (Fig. 5: 2).

Distribución estratigráfica: Viseense medio- superior (Sanz-López et al. 2004).

Gnathodus cf. praebilineatus Belka, 1985

Fig. 5: 3

El elemento $P_{1}$ de esta especie posee una plataforma triangular alargada y se caracteriza por tener un parapeto caudal largo, formado por nódulos o pequeñas crestas transversales, que alcanza normalmente el extremo dorsal del elemento. La parte rostral de la plataforma suele ser lisa u ornamentada con escasos nódulos. El ejemplar hallado 15A-68-1, presenta los caracteres típicos de esta especie, sin embargo, tiene roto el extremo dorsal de la plataforma por lo que se adjudica a ella con alguna reserva.

Distribución estratigráfica: Viseense superior (Nemyrovska and Samankassou, 2005).

\section{Género Lochriea Scott, 1942}

El elemento $P_{1}$ de Lochriea es un pectiniforme carminiescafado

\section{Lochriea commutata (Branson and Mehl, 1941)}

Fig. 5: 13-15

El elemento $P_{1}$ de Lochriea commutata posee una plataforma lisa y ligeramente asimétrica que, en vista oral, presenta un contorno de ovalado a subcuadrado. Los dentículos de la carena tienden a ensancharse lateralmente en la parte dorsal del elemento.

Distribución estratigráfica: Viseense- Serpukhoviense (Barham et al. 2015).

\section{Lochriea costata (Pazuhin and Nemirovskaya en} Kulagina et al. 1992)

Fig. 6: 2

El elemento $P_{1}$ típico de esta especie, posee dos costillas desarrolladas sobre ambos lados de las expansiones basales en una posición central, sin que lleguen a estar conectadas con la carena.

Distribución estratigráfica: Viseense superior-

Serpukhoviense inferior (Barham et al. 2015).

Lochriea monocostata (Pazuhin and Nemirovskaya en Kulagina et al. 1992)

Fig. 6: 1

El elemento $P_{1}$ muestra una única costilla (o un nódulo alargado con forma de cresta) situada sobre la expansión caudal de la cavidad basal. La plataforma presenta un contorno ovalado y un suave entrante en el lado caudal dorsalmente a la posición de la fina costilla.

Distribución estratigráfica: Viseense superiorSerpukhoviense inferior (Barham et al. 2015).

Lochriea ziegleri Nemirovskaya, Perret and Meischner, 1994

Fig. 6: 3 y 4

El elemento $P_{1}$ de esta especie se reconoce porque sobre la plataforma, que presenta un contorno subcuadrado, se desarrollan altas crestas constituidas por nódulos fusionados, siguiendo sus márgenes dorsales, sin llegar a unirse a la carena, pero sí quedan muy próximas a ésta.

Distribución estratigráfica: Serpukhoviense inferior (Barham et al. 2015).

Género Pseudognathodus Park, 1983

Pseudognathodus homopunctatus (Ziegler, 1960) Fig. 5: 11 y 12

El elemento $P_{1}$ de esta especie es carminiescafado y posee una plataforma alta, de ovalada a subtriangu- 
lar, adornada por dos filas de nódulos subparalelos a su carena. Los nódulos que forman la carena pueden estar separados o unidos, al igual que los nódulos que adornan la plataforma. Según Gatovskii and Zhorina (2014) y Sanz-López et al. (2018), este elemento puede presentar diferentes morfotipos. Los elementos: 16A142-2 y 17A-335-1 (Fig. 5: 11 y 12) corresponderían a dos de ellos, el primero con la plataforma menos robusta y las filas de nódulos menos desarrolladas y el segundo con una plataforma más alta y las filas de nódulos bien organizadas

Distribución estratigráfica: Viseense Serpukhoviense inferior (Nemyrovska, 2005)

Familia Palmatolepidae Sweet, 1988 Género Palmatolepis Ulrich and Bassler, 1926

El elemento $P_{1}$ de Palmatolepis es un pectiniforme carminiplano en forma de hoja y con una lámina libre muy corta y un orificio basal casi imperceptible.

\section{Palmatolepis delicatula Branson and Mehl, 1934} Fig. 6: 5 y 6

El elemento $P_{1}$ de esta especie se caracteriza por poseer una plataforma pequeña gruesa y con escasa ornamentación. El margen rostro-dorsal de la plataforma es recto y forma con la lámina libre un ángulo agudo. El lóbulo rostral está muy poco individualizado del resto de la plataforma por lo que esta tiene un contorno casi perfectamente triangular. La carena es sigmoidal y termina en el nódulo central y está formada por pequeños nódulos fusionados. La lámina libre es corta, siendo normalmente inferior a un tercio de la longitud de su plataforma.

Distribución estratigráfica: Devónico Superior,

Fameniense. Zona inferior de triangularis- Zona media de crepida (Ovnatanova et al. 2017).

Palmatolepis glabra prima Ziegler and Huddle 1969 Fig. 6: 14

El elemento $P_{1}$ de esta subespecie presenta una plataforma estrecha, alargada y sigmoidal, y cubierta de pequeños gránulos, que le dan aspecto de lija. Su extremo dorsal es puntiagudo y está girado hacia su parte caudal. La plataforma caudal finaliza antes del extremo dorsal y presenta un margen redondeado. EI área ventral caudal de la plataforma está elevada pero no llega a formarse un verdadero parapeto. Su carena es sigmoidal, y desaparece antes de llegar al extremo dorsal del elemento.
Distribución estratigráfica: Devónico Superior, Fameniense, Zona superior de crepida (Zona glabra prima) - más superior de marginifera (Ovnatanova et al. 2017; Spalletta et al. 2017).

Palmatolepis gracilis gracilis (Branson and Mehl), 1934 Fig. 6: 13

El elemento $P_{1}$ se caracteriza por poseer una plataforma muy estrecha y pequeña, y por presentar una fuerte flexión a la altura del nódulo central, haciendo que los nódulos del inicio de su lámina libre se encuentren desplazados de dicho nódulo. La plataforma interna está algo más desarrollada y su lámina libre tiene una longitud similar a la de la plataforma.

Distribución estratigráfica: Zona superior de rhomboidea (Zona de gracilis gracilis)- Zona de costatus (Sandberg and Ziegler, 1979), zonas rhomboidea-praesulcata (Ovnatanova et al. 2017; Spalletta et al. 2017).

Palmatolepis cf regularis Cooper, 1931

Fig. 6: 10

La plataforma del elemento $P_{1}$ se caracteriza por ser subovalada, sigmoidal, con su extremo dorsal aguzado y con una ornamentación fina constituida por gránulos pequeñísimos que le dan a la superficie un aspecto de lija. La carena se desarrolla en la parte ventral de la plataforma, terminando con una flexión justo antes del prominente nódulo central. El espécimen se clasifica con cf. dado que tiene rota parte de la plataforma rostral

Distribución estratigráfica: Zona superior de crepida (Over, 2007).

\section{Palmatolepis tenuipunctata Sannemann, 1955} Fig. 6: 11 y 12

El elemento $P_{1}$ de esta especie posee una plataforma alargada cuyo lado rostral, en el que se desarrolla un pequeño lóbulo, alcanza el extremo ventral de la lámina libre mientras que el lado caudal se une a la lámina libre en un punto intermedio entre el extremo ventral y el nódulo central. La superficie de la plataforma está cubierta de gránulos diminutos que le dan aspecto de lija. La carena es ligeramente sigmoidal, termina antes de llegar al extremo dorsal.

Distribución estratigráfica: Devónico Superior, Fameniense, Zona superior de triangularis- Zona superior de crepida (Ji and Ziegler, 1993).

Palmatolepis triangularis Sannemann, 1955

Fig. 6: 15 
El elemento $\mathrm{P}_{1}$ posee una gran plataforma con un lóbulo rostral muy prominente situado más ventralmente que el nódulo central y cuya superficie se encuentra profundamente adornada con pequeños tubérculos/ nódulos. Característicamente, la zona dorsal de la plataforma se eleva suavemente a partir del nódulo central. Su carena está suavemente curvada y formada por pequeños nódulos semifusionados que crecen hacia su parte ventral a partir del nódulo central; su parte dorsal termina antes de alcanzar el extremo del elemento.

Distribución estratigráfica: Devónico Superior, Fameniense, Zona de triangularis- Zona media de crepida (Ovnatanova et al. 2017).

Familia Spatognathodontidae Hass, 1959

Género Bispathodus Müller, 1962

Bispathodus stabilis (Branson and Mehl, 1934)

Fig. 6: 16

El elemento $P_{1}$ de esta especie es un elemento carminado que se caracteriza por tener una cavidad basal muy plana con un contorno en forma de gota que se estrecha hacia el extremo dorsal. La unidad presenta una ligera inflexión hacia la mitad centro dorsal y unos dentículos que ganan levemente altura en su parte ventral. Ziegler et al. (1974) diferenciaron dos morfotipos 1 y 2 en función de la longitud de la cavidad basal. El ejemplar 16A-143-3, Fig. 6:16, pertenecería al morfotipo 2 ya que la cavidad basal alcanza el extremo posterior.

Distribución estratigráfica: Zona superior de marginifera (Ziegler and Sandberg, 1984) hasta zona inferior de crenulata (Sandberg et al. 1978).

Género Ozarkodina Branson and Mehl, 1933 Ozarkodina cf. bidentata Bischoff and Ziegler, 1957 Fig. $6: 7$ y 8

El elemento $P_{1}$ del género Ozarkodina es un elemento pectiniforme carminiescafado. Este elemento $\mathrm{P}_{1}$ se caracteriza por poseer dos grupos de dentículos bien diferenciados, unos más estrechos situados en el proceso ventral y otros más gruesos situados sobre el proceso dorsal. El ejemplar 18A-2-5, Fig. 6: 7 y 8 se adjudica a esta especie con reservas dado que se encuentra parcialmente roto.

Distribución estratigráfica: Zona de ensensis (Bultynck, 1987).

\section{Orden Protopanderodontida Sweet, 1988}

Familia Protopanderodontidae Lindström, 1970

\author{
Género Pseudooneotodus Drygant, 1974 \\ Pseudooneotodus beckmanni (Bischoff and \\ Sannemann, 1958)
}

Fig. 5: 16 y 17

Pseudooneotodus beckmanni se caracteriza por poseer un aparato formado por elementos coniformes no geniculados. El elemento $P_{1}$ es cónico y su altura es igual o inferior a la anchura máxima de su base, con un dentículo apical único. El contorno de la base es de ovoidal a subtriangular. La cavidad basal es muy profunda.

\section{Distribución estratigráfica: Ordovícico Medio- Devónico Inferior (Corradini, 2007).}

\section{CAl y estudio de las microtexturas}

El CAI de los elementos estudiados presenta valores comprendidos entre 5 y 6 , con la excepción de los hallados en el corte Loma las Chorreras (UMI), donde el valor del CAl es mucho más bajo y oscila entre 3 y 3,5. Blanco-Ferrera (2011), Blanco-Ferrera et al. (2011) y Sanz-López and Blanco-Ferrera (2012) diferenciaron varios tipos de microtexturas y las relacionaron con diferentes procesos de formación. De acuerdo con estos autores, en los elementos estudiados se han identificado las siguientes (Fig. 8):

- Figura 8, 1. El elemento $\mathrm{P}_{1}$ de Polygnathus sp. (18A-2) con CAI 5 muestra una microtextura de recubrimiento irregular de cristales de sílice rellenando parcialmente la cavidad basal. Los pequeños cristales alargados (más blancos en la imagen) son un artefacto debido a residuos de metatungstato de sodio (identificado mediante EDX) sobre el elemento, que no fue suficientemente bien enjuagado tras la concentración de los conodontos de la muestra.

- Figura 8, 2. En el borde dorso-rostral el elemento $\mathrm{P}_{1}$ de Palmatolepis cf. regularis (18A-6-1) con CAI 5, conserva el patrón poligonal regular de la microtextura inalterada original mientras que en el resto de la superficie se encuentra difuminado o ha desaparecido. La recristalización del apatito origina una microtextura granular. Además, se reconocen microtexturas de disolución.

- Figura 8, 3. El ejemplar $\mathrm{P}_{1}$ de Gnathodus joseramoni (12A-18-1) con CAI 3, muestra sobre la superficie de la plataforma rostral microtexturas de sobrecrecimiento diagenéticas así como la microtextura en contramoldes o la de cristales grandes.

- Figura 8, 4. El ejemplar, un elemento $\mathrm{P}_{1}$ de Lochriea sp. (15A-60-2) con CAI 5.5, presenta microtextura granular producida por la recristalización del apatito. Ade- 
más, presenta microtextura de disolución con grandes oquedades sobre las expansiones de la cavidad basal a las que se encuentran asociados el desarrollo de grandes cristales. Se han analizado estos grandes cristales columnares que, por sus espectros de EDX y hábito, corresponden a precipitados autigénicos de silicatos de aluminio y sodio (feldespatos de tipo albita).

- Figura 8, 5. En las expansiones de la cavidad basal de este elemento $P_{1}$ de Lochriea commutata (17A-3352) con CAI 5.5, se observan microtexturas granulares, de disolución y de recubrimiento irregular, formada por cristales de silicatos, así como pequeñas fracturas.

- Figura 8, 6. Sobre la superficie recristalizada (microtextura granular) de la plataforma del elemento $\mathrm{P}_{1}$ de Pseudognathodus homopunctatus (17A-335-1) con CAI 5.5, se desarrolla una microtextura de recubrimiento irregular que corresponde a una masa desorganizada de silicatos y metales que recuerda a una cristalización en rosetas de, posiblemente, arcillas autigénicas.

Al observar la superficie de los elementos conodontales con el microscopio electrónico de barrido, además de las microtexturas, se han reconocido detalles típicos de la ornamentación de ciertos elementos incluidos en la microtextura inalterada por Blanco-Ferrera (2011).

- Figura, 9, 1. En este elemento $P_{1}$ de Lochriea commutata (16A-336-1), sobre los nódulos de la carena se observa la microornamentación primaria correspondiente a la red poligonal.

- Figura, 9, 2. El elemento de Pseudooneotodus beckmanni (18A-2-3) conserva el cuerpo basal rellenando el interior de la cavidad basal. En la microfotografía de detalle (Fig. 2. a) podemos observar las diferencias texturales entre la superficie lisa de la corona (más mineralizada) y la superficie oquerosa del cuerpo basal (más rico en materia orgánica y por tanto se preserva peor).

\section{Discusión}

\section{Correlación y síntesis estratigráfica}

La Fm. Falcoña se ha utilizado como nivel-guía dado que su presencia es constante en las diferentes secciones (Fig. 3). Por debajo de este nivel aparece una sucesión dominantemente pizarrosa que se ha denominado sucesión pre-Falcoña.Y sobre este nivel-guía, en los cortes de UC aparecen unos delgados niveles de conglomerados con cantos calcáreos e intercalados entre pelitas y anteriores a los conglomerados típicos del Miembro Retamares de la Fm. Almogía, que se incluyen en lo que se ha denominado sucesión
post-Falcoña. La presencia de Lochriea ziegleri permite datar el inicio de la sedimentación post-Falcoña como Serpukhoviense inferior.

\section{Sucesión pre-Falcoña}

La sucesión pre-Falcoña aparece en la mayoría de los cortes, dominada por pelitas y areniscas grauváquicas semejantes a las que se observan en afloramientos de la Fm. Almogía pero que incluyen otros tipos de rocas, en particular lentejones estratificados de calizas del Devónico, de limitada continuidad lateral y pizarras.

En los cortes de la Umbría de Carboneras se encuentran niveles de vulcanoclastitas intercalados estratigráficamente entre las pizarras y arenitas situadas debajo de liditas del corte UC-I. También aparecen en el talud de la pista al Cortijo de la Ermita. Los niveles vulcanoclásticos más gruesos suelen estar intensamente calcitizados y alterados, son lateralmente discontinuos y su espesor puede superar el medio metro. Al E de la Umbría de Carboneras (Cabrera-Porras et al. 2019) así como al S del Cortijo del Mojino, los niveles vulcanoclásticos aparecen entre pelitas, alcanzando desde varios metros hasta algo más de una decena de metros de potencia. En el entorno de estos últimos afloramientos, las pelitas subyacentes a la Fm. Falcoña incluyen cuerpos de rocas magmáticas básicas intrusivas, con texturas faneríticas. Los niveles magmáticos muy alterados intercalados en las pelitas subyacentes a la Fm. Falcoña, hasta la fecha, no habían sido identificados en sucesiones bien datadas del Devónico del Complejo Maláguide. Por ello interpretamos que los cuerpos volcánicos debieron ser de poca entidad, y que han sido desmantelados por completo en muchas áreas de este complejo.

En los cortes de Las Mimbres, UC-V, Mojino I, y Ermita I aparecen calizas con abundantes dacrioconáridos, también algunos han proporcionado conodontos del Devónico Inferior (Mojino I: Pseudooneotodus beckmanni, Ozarkodina cf. bidentata, Polygnathus sp. ver tabla 1). En el corte de La Solana I (parte alta) unas calizas han proporcionado conodontos del Fameniense (Navas-Parejo et al. 2015), confirmados en este trabajo por la presencia de Palmatolepis cf. regularis y Palmatolepis delicatula (Tabla 1). Un afloramiento al $\mathrm{N}$ de la Umbría de Carboneras ha proporcionado abundantes conodontos del Frasniense (zonas MN1 y MN2) descritos en Cabrera-Porras et al. (2019). Todos estos datos demuestran que, en el área estudiada, existe una sucesión siliciclástica con delgadas intercalaciones carbonatadas y vulcanoclásticas, de edad comprendida entre el final del Devónico Inferior y el Carbonífero basal. 
Ángela Cabrera-Porras, et al., 2020. Estudio geológico y bioestratigráfico del Paleozoico... Boletín Geológico y Minero, 131 (4): 831 -855

\section{Sucesión post-Falcoña e inicio del ciclo Culm}

En varios de los cortes del área de estudio, sobre los niveles del miembro superior de calizas de la Fm. Falcoña, aparecen niveles concordantes de pelitas que denotan un marcado cambio en la sedimentación, que pasó a ser de nuevo siliciclástica. Sin embargo, en los cortes de UC-II superior y UC-III (Fig. 3 y Fig. 4), por encima de las calizas viseenses aparece un conglomerado con clastos cuarcíticos y calcáreos con faunas mezcladas del Devónico y Carbonífero. En ambos cortes también se encuentran clastos que contienen conodontos únicamente del Devónico y otros solo del Carbonífero (Ver Fig. 4 y Tabla 1). Dado que estos niveles estratificados de calizas carecen de continuidad lateral y aparecen entre conglomerados, se interpretan como trozos de estratos, incluidos en el conglomerado. Estos grandes fragmentos de estratos tuvieron que haber sido erosionados de un sector de la cuenca comparativamente elevado con respecto al área de depósito de los conglomerados, pero, en cualquier caso, no demasiado alejado de ésta.

Se han reconocido niveles estratificados del Viseense superior-Serpukhoviense inferior en el Complejo Maláguide del sector de Vélez Rubio (Cortijo de Ios González: Navas-Parejo, 2012) y en la ZCV (Corte La Solana I- parte baja: Navas-Parejo et al. 2015). Cerca del corte Cortijo de los González, también aparecen niveles de calizas con conodontos de edad comprendida entre el Bashkiriense basal y el Moscoviense medio, por el hallazgo de Declinognathodus noduliferus e ldiognathoides corrugatus, pero intercalados entre unas pelitas que son cartográfica y estratigráficamente independientes de los niveles de calizas sobre liditas típicos de la Fm. Falcoña (Navas-Parejo et al. 2012). En estos cortes resulta evidente que, en algunas zonas del Complejo Maláguide, existe una sucesión post-Falcoña formada por pelitas con niveles carbonatados cuya edad es anterior al depósito de las facies más características de la Fm. Almogía. Dicha sucesión post-Falcoña probablemente se depositó en el entorno del límite entre el Carbonífero Inferior (Serpukhoviense) y el superior (Bashkiriense inferior). Ésta es posiblemente también la edad de los niveles pelíticos que, en el área de estudio y en otras zonas del Complejo Maláguide, aparecen en concordancia sobre la Fm. Falcoña. Los niveles de conglomerados con conodontos resedimentados y faunas mezcladas del Devónico y Carbonífero encontrados en este trabajo ocupan una posición estratigráfica similar, dado que se sitúan en ligera discordancia sobre la Fm. Falcoña, tras una superficie erosiva, y que contienen un fragmento de estrato de calizas con conodontos del Viseense superiory del Serpukhoviense inicial.

\section{Nuevos datos sobre la estructura y la evolución tér- mica}

La cartografía realizada revela la existencia de diferentes etapas de deformación durante la Orogenia Alpina en el Complejo Maláguide de la ZCV, en las que también están involucrados los terrenos triásicos y más modernos. La primera deformación alpina detectada fue responsable de la formación de cabalgamientos y pliegues asociados vergentes al SE, deducidos a partir de la orientación de la estratificación a lo largo del mapa (Fig. 2) y de mediciones de la orientación de ejes de pliegues visibles en afloramiento. Esta etapa fue seguramente la responsable de la individualización de las tres grandes unidades maláguides alpinas reconocibles en la zona (UME, UMI y UMS). Los contactos de cabalgamiento se observan limpiamente en muchos puntos como superficies netas asociadas a bandas estrechas de deformación entre terrenos pardos del Paleozoico (bloque de techo) y rojos del Triásico (bloque de muro). Las medidas de la estratificación (planos y polos) muestran una dirección OSO-ENE dominante, así como una mayor tendencia de los buzamientos hacia NNO. Del mismo modo, también se observa gran cantidad de planos con la misma dirección, pero buzando en sentido contrario. Estos pliegues se interpretan como asociados a los cabalgamientos representados en la cartografía ya que su dirección es similar $y$, además, se suelen encontrar en sus inmediaciones.

Una etapa de deformación posterior a los cabalgamientos generó las fallas de salto en dirección y normales que desplazan los contactos estratigráficos y las trazas de los cabalgamientos. Con seguridad dichas fallas cortan también a la UME, aunque no se han estudiado con detalle en dicha unidad ya que no se ha procedido a su cartografía precisa. En definitiva, la propuesta de subdivisión del Complejo Maláguide en varias unidades tectónicas alpinas, inicialmente descrita en el área de Vélez Rubio y luego reconocida en otras áreas (Navas-Parejo, 2012 y referencias allí incluidas) también se reconoce en la ZCV.

\section{Interpretación paleoambiental y paleogeográfica}

Los datos obtenidos indican que la sucesión pre-Falcoña de la UMS se depositó entre el final del Devónico Inferiory el inicio del Carbonífero, en ambientes marinos abiertos con sedimentación esencialmente siliciclástica en condiciones de baja energía. En épocas de menor aporte terrígeno se depositaron delgados niveles de calizas con fauna planctónica de dacrioconáridos y conodontos. Todo ello sugiere ambientes marinos profundos, aunque no tanto como los de las sucesiones tipo Santi Petri de la UMI. Estas últimas, dominadas 
por turbiditas, caracterizaban las partes más profundas y distales de la Cuenca Maláguide en el Devónico (Rodríguez-Cañero and Martín-Algarra, 2014).

La sucesión pre-Falcoña muestra una tendencia a la profundización que culminó con el depósito del miembro inferior (liditas) de la Fm. Falcoña, representado por radiolaritas depositadas bajo el nivel de compensación de los carbonatos (CCD). Los momentos de máxima profundización estuvieron precedidos de cierta inestabilidad tectónica, lo que favoreció un vulcanismo explosivo que generó niveles vulcanoclásticos. Esta evolución caracteriza la fase de madurez de un margen continental divergente y marca el momento de máxima apertura y profundización del mismo al inicio del Carbonífero al generalizarse la subsidencia térmica y uniformizarse su paleotopografía. Un posterior descenso del CCD permitió el depósito de las calizas de la Fm. Falcoña.

La homogeneidad de las facies de los dos miembros de la Fm. Falcoña y su reducido espesor a escala regional indican que, durante la mayor parte del Carbonífero Inferior las condiciones sedimentarias en la Cuenca Maláguide fueron uniformes y con baja tasa de sedimentación. Estas condiciones indican ambientes propios de una cuenca distal, extensa, Ilana, muy profunda, a la que solo llegaban escasos aportes pelágicos biogénicos y que estaba casi completamente desprovista de aportes siliciclásticos. En el área estudiada se observan rasgos que indican que las condiciones sedimentarias de la Cuenca Maláguide estaban empezando a cambiar en el Viseense terminal o Serpukhoviense inicial. En efecto, el bloque estratificado noduloso con fauna de esta edad incluido en el conglomerado con clastos calcáreos del Devónico y Carbonífero del corte UC-III, indica que su depósito tuvo lugar en zonas algo menos profundas de la cuenca, posiblemente en ambientes de alto fondo pelágico con baja tasa de sedimentación. Por tanto, durante el final del depósito de la Fm. Falcoña, la topografía de la Cuenca Maláguide comenzaba a cambiar. Al acentuarse estas irregularidades del fondo de la cuenca, la posición original de las calizas nodulosas en zonas topográficamente elevadas favoreció su desmantelamiento erosivo y su redepósito en las áreas deprimidas adyacentes tras un limitado transporte. Así, los grandes bloques de calizas nodulosas, quedaron incluidos en conglomerados ligeramente discordantes y erosivos sobre la Fm. Falcoña.

En definitiva, el depósito del conglomerado con bloques de estratos de calizas nodulosas y clastos calcáreos con conodontos del Devónico y Carbonífero de los cortes de la Umbría de Carboneras sugiere una evolución de la Cuenca Maláguide, desde una etapa tectónicamente tranquila y dominada por la subsi- dencia térmica propia de la etapa de madurez de un margen continental divergente durante el Tournaisiense-Viseense, a otra relacionada con inestabilidades tectónicas sinsedimentarias progresivamente crecientes a partir del Viseense terminal-Serpukhoviense temprano. Dicha evolución es la propia de un margen continental convergente durante su etapa inicial.

La división en dos partes de los cortes UC-II y UC-IV y de la Solana I, donde las sucesiones estratigráficas del Devónico y Misisípico aparecen duplicadas por causas tectónicas, con los terrenos de la Fm. Falcoña plegados y recubiertos en discordancia por el conglomerado descrito y por los depósitos sucesivos de la Fm. Almogía, podría relacionarse con esta fase de inicio de las deformaciones del fondo de la cuenca que se acaban de mencionar. Esta fase marcaría, por tanto, el inicio de la evolución orogénica pre-Alpina (tardi-Varisca) del Complejo Maláguide, que se generalizaría con el depósito de grandes volúmenes de sedimentos siliciclásticos en la Fm. Almogía, a partir del tránsito entre el Misisípico y el Pensilvánico. En síntesis, esta sucesión de eventos se relaciona con las fases más tempranas del comienzo tardío de la Orogenia Varisca (Hercínica) en el sector occidental del margen septentrional del Paleotethys, del que el Complejo Maláguide formaba parte durante su evolución paleogeográfica paleozoica (Rodríguez-Cañero and Martín-Algarra, 2014; Martín-Algarra et al. 2019).

\section{Conclusiones}

Las contribuciones más destacadas de este trabajo son las siguientes:

1. La sucesión pre-Falcoña incluye niveles delgados de areniscas, rocas vulcanosedimentarias y calizas con conodontos del Devónico y muestra características litoestratigráficas muy diferentes de las de la Fm. Santi Petri.

2. En la sucesión pre-Falcoña se ha confirmado la presencia de niveles de conodontos del Emsiense, del Frasniense y del Fameniense, reconocida en estudios previos.

3. El aporte siliciclástico fino relacionado con el depósito de la sucesión post-Falcoña se demuestra que se inició a partir del Serpukhoviense temprano asociado al depósito de un nivel conglomerático con cantos y bloques calcáreos con mezcla de fauna de conodontos del Devónico y del Carbonífero.

4. Un bloque estratificado de calizas nodulosas incluido en el conglomerado contiene una fauna de conodontos del Viseense superior y del Serpukhoviense inicial, edad coetánea de la parte superior las calizas de la Fm. Falcoña. 
5. Nuestros datos apoyan la subdivisión del Complejo Maláguide de la ZCV en tres unidades tectónicas alpinas: Unidad Maláguide Epimetamórfica, Unidad Maláguide Inferior y Unidad Maláguide Superior, reconocidas previamente por otros autores.

6. Se diferencian dos etapas de deformación durante la Orogenia Alpina, que producen, respectivamente, pliegues y cabalgamientos vergentes al $\mathrm{S}$ y fallas tardías de salto en dirección (principalmente dextrorsas) y normales.

7. Se aportan los primeros datos del CAI junto con un estudio preliminar de las alteraciones de la microtextura de los conodontos en la ZCV, que pone de manifiesto que la historia térmica de las unidades Maláguides Superior e Inferior es diferente, lo que deberá ser confirmado y explicado en estudios posteriores.

\section{Agradecimientos}

ACP agradece de un modo especial a Alejandro Ruiz Fuentes, por su apoyo incondicional y ayuda durante muchísimas de las jornadas de campo realizadas, y también a los profesores Antonio Sánchez-Navas y Alberto Pérez-López, de los departamentos de Mineralogía y Petrología y de Estratigrafía y Paleontología de la Universidad de Granada, por haber permitido la realización de este trabajo con fondos del proyecto CGL2016-75679P (Ministerio de Economía y Competitividad) y del Grupo de investigación RNM208 (Junta de Andalucía). Agradecemos a los Dres. Silvia Blanco-Ferrera y Sergio Rodríguez García sus cuidadosas revisiones, las cuales nos han ayudado a mejorar este trabajo.

\section{Referencias}

Anderson, M.A., Dargan, G., Brock, G.A., Talent, J.A. and Mawson, R. 1995. Maximizing efficiency of conodont separations using sodium polytungstate solution. Courier Forschungsinstitut Senckenberg, 182, 515-521.

Austin, R.L. and Husri, S. 1974. Dinantian conodont faunas of County Clare, County Limerick and County Leitrim, An Appendix. In: Bouckaert, J., Streel, M. (Eds.), International Symposium on Belgian Micropaleontological Limits - Namur 1974. Geological Survey of Belgium, Brussels, pp. 18-69.

Austin, R.L. and Rhodes, F.H.T. 1981. Family Elictognathidae (p. W170-W172). In: Robinson, R. A., et al. (editors), Conodonts, Miscellanea, Supplement 2, Treatise of Invertebrate Paleontology, Geological Society of America, Part W, 202 pp.

Barham, M., Murray, J., Sevastopulo, G.D. and Williams, D.M. 2015. Conodonts of the genus Lochriea in Ireland and the recognition of the Viséan-Serpoukhovian (Carboniferous) boundary. Lethaia, 48, 151-171.

Belka, Z. 1985. Lower Carboniferous conodont biostratigraphy in the northeastern part of the Moravia-Silesia basin. Acta Geologica Polonica, 35, 33-60.

Bermúdez Rochas, D. D. 2003. Estudio de los conodontos del Viseense superior de la Unidad de la Sierra del Castillo (Córdoba, Carbonífero)Tesis doctoral Univ. Complutense, Madrid, 159 pp.

Bischoff, G. and Sannemann, D. 1958. Unterdevonische Conodonten aus dem Frankelwald. Hessisches landesamt für bodenforschung, Notizblatt, 86, 87-110.

Bischoff, G and Ziegler, W. 1957. Die Conodontenchronologie des Mitteldevons und des tiefsten Oberdevons. Abhandlungen des Hessischen Landesamtes für Bodenforschung, 22, 1-136.

Blanco-Ferrera, S. 2011. Los conodontos y la evolución tectonotérmica del sector noreste de la Zona Cantábrica.Tesis Doctoral, Universidad de Oviedo, 296 pp.

Blanco-Ferrera, S., García-López, S. and Sanz-López, J. 2005. Conodontos carboníferos de la sección del río Cares (Unidad de Picos de Europa, Zona Cantábrica, NO de España). Geobios, 38, 17-27.

Blanco-Ferrera, S., Sanz-López, J., García-López, S., Bastida, F. and Valín, M.L. 2011. Conodont alteration and tectonothermal evolution of a diagenetic unit in the Iberian Variscan belt (Ponga Cuera unit, NW Spain). Geological Magazine, 148, 35-49.

Blumenthal, M. 1927. Versuch einer tektonischen Gliederung der Betischen Cordilleren von Central und Südwest Andalusien. Eclogae Geologicae Helvetiae, XX, 487-532.

Blumenthal, M. 1949. Estudio geológico de las cadenas costeras al oeste de Málaga entre el río Guadalhorce y el río Verde. Boletín Geológico y Minero, 62, 11-203.

Blumenthal, M. and Fallot, P. 1935. Observations géologiques sur la Sierra Arana entre Grenade et Guadix. Memorias de la Sociedad Española de Historia Natural, XVIII, 1-74.

Branson, E.B. and Mehl, M.G. 1933. Conodonts from the Bainbridge Formation (Silurian) of Missouri. University of Missouri Studies, 8(1), 5-72.

Branson, E.B. and Mehl, M.G. 1934. Conodonts from the Grassy Creek shale of Missouri. University of Missouri Studies, 8(3), 171-259.

Branson, E.B. and Mehl, M.G. 1941. New and little-known Carboniferous conodont genera. Journal of Paleontology, 15, 97-106.

Bultynck, P. 1987. Pelagic and neritic conodont successions from the Givetian of pre-Sahara Morocco and the Ardennes. Bulletin de I'Institut Royal des Sciences Naturelles de Belgique, Science de la Terre, 57, 149-181.

Cabrera-Porras, A., Rodríguez-Cañero, R. and Martín-Algarra, A. 2019. Primeros conodontos del Frasniense en el Complejo Maláguide de Granada (Cordillera Bética). Spanish Journal of Palaeontology, 34 (2), 155-178. 
Ángela Cabrera-Porras, et al., 2020. Estudio geológico y bioestratigráfico del Paleozoico... Boletín Geológico y Minero, 131 (4): 831 -855

Cooper, C. L. 1931. New conodonts from the Woodford formation of Oklahoma. Journal of Paleontology, 5, 230-243.

Corradini, C. 2007. The conodont genus Pseudooneotodus Drygant from the Silurian and Lower Devonian of Sardinia and the Carnic Alps (Italy). Bollettino della Società Paleontologica Italiana, 46, 139-148.

Drygant, D.M. 1974. Prostye konodonty silura i nizov Devona Volyno-Podol'ya (Simple conodonts from the Silurian and lowermost Devonian of Volyno-Podolia). Paleontologicheskii Sbornik, 10, 64-70 [en Ruso].

Durand-Delga, M. 1968. Coup d'oeil sur les unités malaguides des Cordillères bétiques (Espagne). Comptes Rendus de I'Académie des Sciences de Paris, 266, 190-193.

Dzik, J. 1976. Remarks on the evolution of Ordovician conodonts. Acta Palaeontologica Polonica, 21, 395-455.

Epstein, A.G., Epstein, J.B. and Harris, L.D. 1977. Conodont Color Alteration: an Index to Organic Metamorphism. U.S. Geological Survey Professional Papers, 995, 1-27.

García-López, S. 1984. Terminología morfológica de conodontos compuestos y de plataforma. Revista de Biología de la Universidad de Oviedo, 2, 95-105.

Gatovskii, Y.A. and Zhokina, M.A. 2014. The ontogenesis of several Late Visean conodonts from the Verkhnyaya Kardailovka section (Southern Urals). Moscow University Geology Bulletin, 69, 452-457. https://doi.org/10.3103/ S0145875214060064.

Geel, T. 1973. The geology of the Betic of Malaga, the Subbetic, and the zone between these two units in the Vélez Rubio area (southern Spain). GUA Papers of Geology, 1(5), 1-181.

Haeckel, E. 1874. Anthropogenie oder Entwicklungsgeschichte des Menschen. Engelmann, Leipzig, 732 pp.

Hartenfels, S. 2011. Die globalen Annulata-Events und die Dasberg-Krise (Famennium, Oberdevon) in Europa und Nord-Afrika: hochauflösende Conodonten-Stratigraphie, Karbonat-Mikrofazies, Paläoökologie und Paläodiversität. Münstersche Forschungen zur Geologie und Paläontologie, 105, 17-527.

Hass, W.H. 1953. Conodonts of the Barnett Formation of Texas. United States Geological Survey Professional Paper, 243F, 6994.

Hass, W.H. 1959. Conodonts of the Barnett Formation of Texas. United States Geological Survey Professional Paper, 243, 69-94.

Herbig, H.G. 1983. El Carbonífero de las Cordilleras Béticas. $X$ Congreso Internacional de Estratigrafía y Geología del Carbonífero (E. Martínez-García, Coord.). Instituto Geológico y Minero de España, Madrid, 343-356.

Herbig, H.G. 1984. Rekonstruktion eines nicht mehr existenten Sedimentationsraumes - Die Kalkgerolle mit Karbon-Flysch der Malagiden (Betische Kordillere, Südspanien). Facies, 11, 1-108.

Herbig, H.G. 1985. An Upper Devonian limestone slide block near Marbella (Betic Cordillera, southern Spain) and the paleogeographic relations between Malaguides and Menorca. Acta Geologica. Hispanica, 21, 155-178.

Herbig, H.G. and Mamet, B. 1985. Stratigraphy of the limestone boulders, Marbella Formation (Betic Cordillera, Southern Spain). Comptes Rendus du 10 ${ }^{\text {ème }}$ Congres International de Stratigraphie et de Géologie du Carbonifère, Madrid, Vol. 1, 199-212.

Jeppsson, L, Anehus, R. and Fredholm, D. 1999. The optimal acetate buffered acetic acid technique for extracting phosphatic fossils. Journal of Paleontology, 3(5), 964-972.

Ji, Q. and Ziegler, W. 1993. The Lali Section: An excellent Reference section for Upper Devonian in South China. Courier Forschungsinstitut Senckenberg, 188, 99-101.

Kockel, F. and Stoppel, D. 1962. Nuevos hallazgos de conodontos y algunos cortes en el Paleozoico de Málaga (Sur de España). Notas y Comunicaciones del Instituto Geológico y Minero de España, 68, 133-170.

Kulagina, E.I., Rumyantseva, Z.S., Pazukhin, V.N. and Kochetova, N.N. 1992. Granitsa nizhnego-srednego karbona naYuzhnom Urale i Srednem Tyan'-Shane (The Lower-Middle Carboniferous Boundary in the South Urals and Central Tien-Shan). Nauka, Moscow, 112 pp.

Lindström, M. 1970. A suprageneric taxonomy of the conodonts. Lethaia, 3, 427-445.

Martín-Algarra, A. 1987. Evolución geológica alpina del contacto entre las Zonas Internas y las Zonas Externas de la Cordillera Bética.Tesis Doctoral, Universidad de Granada, 1171 pp.

Martín-Algarra, A., Solé de Porta, N. and Maate, A. 1995. El Triásico del Maláguide- Gomáride (Formación Saladilla, Cordillera Bética Occidental y Rif Septentrional). Nuevos datos sobre su edad y significado paleogeográfico. Cuadernos de Geología Ibérica, 19, 249-278.

Martín-Algarra, A. (coordinador), Martín-Martín, M., Estévez, A., López-Garrido, A.C., Alonso-Chaves, F.J., Andreo, B., Balanyá, J.C., González-Lodeiro, F., Jabaloy, A., Orozco, M. and Sanz de Galdeano, C. 2004. Estructura del Complejo Maláguide. In: Vera, J.A. (Ed.), Geología de España. Sociedad Geológica Española - Instituto Geológico y Minero de España, Madrid, 407-409.

Martín-Algarra, A., Mazzoli, S., Perrone, V., Rodríguez-Cañero, R. and Navas-Parejo, P. 2009a. Variscan tectonics in the Malaguide Complex (Betic Cordillera, Southern Spain): stratigraphic and structural Alpine vs. pre-Alpine constraints from the Ardales area (Province of Malaga). I: Stratigraphy. The Journal of Geology, 117, 241-262.

Martín-Algarra, A., García-Casco, A., Gómez-Pugnaire, M.T., Jabaloy-Sánchez, A., Laborda-López, C., López Sánchez-Vizcaíno, V., Mazzoli, S., Navas-Parejo, P., Perrone, V., Rodríguez-Cañero, R. and Sánchez-Navas A. 2019. Paleozoic Basement and Pre-Alpine History of the Betic CordiIlera. In: Quesada, C. and Oliveira, J.T. (Eds.), The Geology of Iberia: A Geodynamic Approach, Vol. 2, (Alpine Cycle, J. Vergés and J.C. Kullber, Volume Coordinators), Ch. 9, p. 261-305. Regional Geology Reviews. Springer Nature. 
Ángela Cabrera-Porras, et al., 2020. Estudio geológico y bioestratigráfico del Paleozoico... Boletín Geológico y Minero, 131 (4): 831 -855

Martín-Martín, M. 1996. El Terciario del Dominio Malaguide en Sierra Espuña (Cordillera Bética oriental, SE de España). Tesis Doctoral, Universidad de Granada, 299 pp.

Michelau, P. 1941. Das Paläozoikum der Betischen Ketten nordwestlich von Malaga. PhD Dissertation, Universidad de Berlín (inédita), 26 pp.

Mon, R. 1971. Estudio geológico del extremo occidental de los Montes de Málaga y de la sierra de Cártama (Prov. de Málaga). Boletín Geológico y Minero, 82, 132-146.

Müller, K.J. 1962. Supplement to systematics of conodonts. In: Moore, R.C. (Ed.), Treatise on Invertebrate Paleontology. Geological Society of America and University of Kansas, PartW, Miscellanea:W246-W249. NewYork and Lawrence.

Navarro-Vilá, F. and García-Dueñas, V. 1980. Mapa Geológico de España 1:50.000, Hoja 1010 (La Peza). Instituto Geológico y Minero de España, Madrid.

Navas-Parejo, P. 2012. Paleozoic Stratigraphy and Palaeogeography of the Malaguide Complex (Betic Cordillera) and other Western Mediterranean related domains (Calabria-Peloritani Terrane). Tesis Doctoral, Universidad de Granada, 219 pp.

Navas-Parejo, P., Martín-Algarra, A. and Martínez-Pérez, C. 2011. Primeros datos sobre la presencia de conodontos del Emsiense (Devónico Inferior) en el Complejo Maláguide de la provincia de Granada. Paleontologia i Evolució, Memòria especial, 5, 425-429.

Navas-Parejo, P., Rodríguez-Cañero, R. and Martín-Algarra, A. 2012. Primer registro de un horizonte estratigráfico hemipelágico con conodontos del Carbonífero Superior en el Complejo Maláguide (Cordillera Bética oriental). Geogaceta, 52, 81-84.

Navas-Parejo, P., Rodríguez-Cañero, R. and Martín-Algarra, A. 2015. New conodont data from a Devonian-Carboniferous succession in the central sector of the Betic Cordillera. Spanish Journal of Palaeontology, 30, 133-145.

Nemirovskaya, T.I. with an appendix by Samankassou, E. 2005. Late Viséan/early Serpukhovian conodont succession from the Triollo section, Palencia (Cantabrian Mountains, Spain). Scripta Geologica, 129, 13-89.

Nemirovskaya, T.I., Perret, M. and Meischner, D. 1994. Lochriea ziegleri and Lochriea senckenbergica- New conodont species from the latest Visean and Serpukhovian in Europe. Courier Forschungsinstitut Senckenberg, 168, 311-317.

O’Dogherty, L., Rodríguez-Cañero, R., Gursky, H.J., Martín-Algarra, A. and Caridroit, M. 2000. New data on Lower Carboniferous stratigraphy and palaeogeography of the Malaguide Complex (Betic Cordillera, Southern Spain). Comptes Rendus de I'Academie des Sciences Paris, Serie II, 331, 533-541.

Orueta, D. 1917. Estudio geológico y petrográfico de la Serranía de Ronda. Memorias del Instituto Geológico y Minero de España, 32, 1-576.

Over, D. 2007. Conodont biostratigraphy of the Chattanooga Shale, Middle and Upper Devonian, southern Appala- chian basin, eastern United States. Journal of Paleontology, 81, 1194-1217.

Ovnatanova, N.S., Kononova, L.I., Kolesnik, L.S. and Gatovsky,Y.A. 2017. Upper Devonian conodonts of Northeastern European Russia. Journal of Paleontology, 51, 973-1165.

Pander, C.H. 1856. Monographie der fossilen Fische des silurischen Systems der russisch-baltischen Gouvernements. Akademie derWissenschaften, 91 pp.

Park, S.I. 1983. Zonenfolge, Phylogenie und Taxonomie karbonischer Conodonten zwischen Tournai und Westfal (Westeuropa). PhDThesis, Philipps-Universität Marburg, 187 pp.

Perri, M.C. and Spalletta, C. 1998. Conodont distribution at the Tournaisian/Viséan boundary in the Carnic Alps (southern Alps, Italy). In: Szaniawski, H. (Ed.), Proceedings of the Sixth European Conodont Symposium (ECOS VI). Palaeontologica Polonica, 58, 225-245.

Purnell, M.A., Donoghue, P.C.J. and Aldridge, R.J. 2000. Orientation and anatomical notation in conodonts. Journal of Paleontology, 74, 113-122.

Rejebian, V.A., Harris, A.G. and Huebnerm, J.S. 1987. Conodont color and textural alteration: An index to regional metamorphism, contact metamorphism, and hydrothermal alteration. Geological Society of America Bulletin, 99, 471-479.

Rico-Colmenero, J. 2015. Geología de un sector del Complejo Maláguide al frente de las Zonas Internas al NE de Granada. Trabajo de Fin de Grado en Geología, Universidad de Granada (inédito), 24 pp.

Rodríguez-Cañero, R. 1993. Contribución al estudio de los conodontos del Paleozoico del Complejo Maláguide (Cordillera Bética). Tesis Doctoral, Universidad de Málaga (inédito), 474 pp.

Rodríguez-Cañero, R. and Guerra-Merchán, A. 1996. Nuevos datos sobre la fauna de conodontos y la edad de la Formación Falcoña (Complejo Maláguide, Cordillera Bética, España). Revista Española de Paleontología, 11, 235-246.

Rodríguez-Cañero, R. and Martín-Algarra, A. 2014. Frasnian-Famennian crisis in the Malaguide Complex (Betic Cordillera, Spain). Terra Nova, 26, 38-54.

Rodríguez-Cañero, R., Martín-Algarra, A., Sarmiento, G.N. and Navas-Parejo, P. 2010. First Late Ordovician conodont fauna in the Betic Cordillera (South Spain): a palaeobiogeographical contribution. Terra Nova, 22, 330-340.

Rodríguez-Cañero, R., Jabaloy-Sánchez, A., Navas-Parejo, P. and Martín-Algarra, A. 2018. Linking Palaeozoic palaeogeography of the Betic Cordillera to the Variscan Iberian Massif: new insight through the first conodonts of the Nevado-Filábride Complex. International Journal of Earth Sciences, 107, 1791-1806.

Roundy, P.V. 1926. Introduction, the microfauna in Mississipian formations of Saba County, Texas. U.S. Geological Survey Professional Paper, 146, 1-46.

Ruiz Cruz, M.D. and Nieto, J. M. 2002. Condiciones P-T de estabilidad de las fases vermiculíticas en metaclastitas de 
la zona de Málaga (Cordillera Bética). Congreso de Mineralogía y Petrología SEM 2002.

Ruiz Cruz, M.D. and Sanz de Galdeano, C. 2010. Factors controlling the evolution of mineral assemblages and illite crystallinity in Paleozoic to Triassic sequences from the transition between Maláguide and Alpujárride complexes (Betic Cordillera, Spain): the significance of tobelite. Clays and Clay Minerals, 58, 558-572.

Ruiz Cruz, M.D., Sanz de Galdeano, C. and Lázaro, C. 2005. Metamorphic evolution of Triassic rocks from the transition zone between the Malaguide and the Alpujarride complexes (Betic Cordilleras, Spain). European Journal of Mineralogy, 17, 81-91.

Sandberg, C.A. and Ziegler, W. 1979. Taxonomy and biofacies of important conodonts of Late Devonian styriacus-Zone, United States and Germany. Geologica et Palaeontologica, 13, 173-212.

Sandberg, C.A., Ziegler, W., Leuteritz, K. and Brill, S.M. 1978. Phylogeny, speciation and zonation of Siphonodella (Conodonta, Upper Devonian and Lower Carboniferous). Newsletters on Stratigraphy, 7, 102-120. https://doi. org/10.1127/nos/7/1978/102.

Sannemann, D. 1955. Beitrag zur untergliederung des Oberdevons nach Conodonten. Neues Jahrbuch für Geologie und Paläontologie, Abhandlungen, 100, 324-331.

Sanz de Galdeano, C., Delgado, F. and López-Garrido, A.C. 1995. Estructura del Alpujárride y del Maláguide al NW de Sierra Nevada (Cordillera Bética). Revista de la Sociedad Geológica de España, 8, 239-250.

Sanz-López, J. and Blanco-Ferrera, S. 2012. Revisión estratigráfica del Misisipiense al Pensilvaniense más bajo de la zona Cantábrica y la posición de los límites entre los pisos. VIII Congreso Geológico de España, Geotemas, 13, 90.

Sanz-López, J., Blanco-Ferrera, S. and García-López, S. 2004. Taxonomy and evolutionary significance of some Gnathodus species (conodonts) from the Mississippian of the Northern Iberian Peninsula. Revista Española de Micropaleontología, 36, 215-230.

Sanz-López, J., Blanco-Ferrera, S. and Miller, C. 2018. Morphologic variation in the P1 element of the Mississippian species of the conodont genus Pseudognathodus. Revista Española de Paleontología, 33, 185-204. https://doi. org/10.7203/sjp.33.1.13248.

Scott, H.W. 1942. Conodont assemblages from the Heath formation, Montana. Journal of Paleontology, 16, 293300.

Soediono, H. 1971. Geological investigations in the Chirivel area, province of Almería, southeastern Spain. Tesis Doctoral, Universidad de Amsterdan, 144 pp.

Spalletta, C., Perri, M.C., Over, D.J. and Corradini, C. 2017. Famennian (Upper Devonian) conodont zonation: revised global standard. Bulletin of Geosciences, 92 (1), 31-57. https://doi.org/10.1340/bull.geosci.1623.

Sweet, W.C. 1988. The conodonta. Oxford monographs on Geology and Geophysics, Clarendon Press, Oxford, 212 pp.

Ulrich, E.O. and Bassler, R.S. 1926. A classification of the toothlike fossils, conodonts, with description of American Devonian and Mississippian species. Proceedings of the United States National Museum, 68, 1-63.

Vera, J.A. 2004. Geología de España. Sociedad Geológica de España - Instituto Geológico y Minero de España, Madrid, $884 \mathrm{pp}$.

Ziegler, W. 1960. Die Conodonten aus den Geröllen des Zechsteinkonglomerates von Rossenray (südwestlich Rheinberg/Niederrhein) mit der Beschreibung einiger neuen Conodontenformen. Fortschitte in der Geologie von Rheinland und Westfalen, 6, 391-406.

Ziegler, W. and Huddle, J.W. 1969. Die Palmatolepis glabra-Gruppe (Conodonta) nach der Revision der Typen von Ulrich \& Bassler durch J.W. Huddle. Fortschritte in der Geologie von Rheinland und Westfalen, 16, 377-386

Ziegler, W. and Sandberg, C.A. 1984. Palmatolepis-based revision of upper part of standard Late Devonian conodont zonation. In: Clark, D.L. (Ed.), Conodont biofacies and provincialism, Geological Society of America Special Paper 196, 179-194.

Ziegler, W., Sandberg, C.A. and Austin, R.L. 1974. Revision of Bispathodus group (Conodonta) in the Upper Devonian and Lower Carboniferous. Geologica et Palaeontologica, 8, 97-112.

Recibido: julio 2019

Revisado: noviembre 2019

Aceptado: enero 2020

Publicado: marzo 2021 